\title{
Key events in the history of cardiac surgery and paediatric cardiolog * $^{*}$
}

\author{
Tom R. Karl, ${ }^{1,2}$ Gerard R. Martin, ${ }^{3}$ Jeffrey P. Jacobs, ${ }^{1,2}$ Gil Wernovsky ${ }^{4}$ \\ ${ }^{1}$ Division of Cardiovascular Surgery, Jobns Hopkins All Children's Heart Institute, Jobns Hopkins All Children's \\ Hospital, Saint Petersburg, Florida; ${ }^{2}$ Departments of Surgery and Pediatrics, Johns Hopkins University, Baltimore, \\ Maryland; ${ }^{3}$ Department of Cardiology, Children's National Health System, Washington, \\ District of Columbia; ${ }^{4}$ Division of Critical Care Medicine, Children's National Health System, Washington, District \\ of Columbia, United States of America
}

\begin{abstract}
In this report, the authors prepared an opinion poll regarding the most important people, events, technologies, concepts, discoveries, and therapies in paediatric cardiology and cardiac surgery. The results were presented in continuous slide show format at the 2017 Seventh World Congress of Pediatric Cardiology \& Cardiac Surgery (WCPCCS 2017), Barcelona, Spain. The presentation (under international copyright) is made available herein for educational purposes.
\end{abstract}

Keywords: Pediatric cardiology; cardiac surgery; history

Received: 21 November 2017; Accepted: 5 December 2017

All we know is still infinitely less than all that remains unknown.

$$
\text { William Harvey (1578-1657) }
$$

The 2017 World Congress of Pediatric Cardiology and Cardiac Surgery (WCPCCS 2017) was held in Barcelona, Spain, from 16 to 21 July, 2017. In preparation for this congress, which itself promised to be a significant historic initiative, the authors, on invitation of the organising committee, took the initiative to nominate the most important events that have shaped our speciality. The history of paediatric cardiology is rich and fascinating. However, it is fair to say that our own era of complex diagnostic imaging, sophisticated intensive care, and neonatal openheart surgery comprises a very small portion of the timeline (Fig 1). If one were to take the work of Galen (de Curandi, c. 162 AD) as time 12:01 AM in a single day and the WCPCCS 2017 as midnight, then

*Presented at the 2017 Seventh World Congress of Pediatric Cardiology \& Cardiac Surgery (WCPCCS 2017), Barcelona, Spain, 16-21 July, 2017. Presented Friday, 21 July, 2017.

Correspondence to: Professor T. R. Karl, Johns Hopkins All Children's Heart Institute, Johns Hopkins All Children's Hospital, 601, 5th St. South, Suite 607, St. Petersburg, FL 33701, United States of America. Tel: +1 727303 9511; E-mail: Trkarl.aus@gmail.com cardiopulmonary bypass would not appear until 11:26 PM. The Raskind septostomy would appear around 11:26 PM, and the Norwood operation around 11:40 PM. This brings to mind the often quoted words of Isaac Newton, who said, paraphrasing Bernard de Chartres, that "If I have seen further, it is by standing on the shoulders of giants". This statement, to be sure, constitutes the essence of progress and discovery in any field. Yet, amidst the complexities and demands of our own careers, it is sometimes easy to overlook this fact. Our aim in undertaking this study was to document, present, and further preserve some of the key events and contributions that have brought us to the point of the 2017 World Congress. In doing so, we sought to recognise and honour the many great contributors of past and present eras, and to place our own careers in a realistic perspective. The results of the survey were tabulated and the authors prepared a presentation of the outcome in the format of a continuous "slide show", which was displayed in various venues of the Convention Center between scientific presentations of the WCPCCS 2017.

\section{Method}

To assess the relative importance of the many contributions that have influenced our speciality, we 
conducted an opinion poll among paediatric cardiologists, cardiac surgeons, and cardiac intensivists, all of whom were currently working in these capacities in various parts of the world. The methodology involved writing to a selection of eminent practitioners who were known to the authors and perhaps more likely to respond ("convenience sample"). The question posed was, by intent, somewhat free form. Respondents were asked to nominate as many events, people, technologies, concepts, discoveries, and so on as they desired. The unifying thread was that the choices would be considered outstanding or seminal in the history of paediatric cardiology and cardiac surgery. No time constraints were imposed, allowing nominations from any period, including the present. No justification for the choices was required, and the responses represent personal expert opinions, which, by design, were not necessarily evidence based.

\section{Results}

In all, 86 individuals were invited to offer an opinion. From this group, there were 48 respondents (56\%) for whom a breakdown is given in Figure 1. There were 28 cardiologists and intensivists $-58 \%$ of respondents and 20 surgeons $-42 \%$ of respondents - representing 16 countries in Australasia, North America, Africa, Europe, and the Middle East. The authors collated the responses and grouped them by the number of nominations for each category. Some of the responses could have been assigned to multiple categories, but were counted only once. Nominations were grouped according to the number of times each was submitted. Ultimately, the 50 highest scoring nominations were included in the WCPCCS presentation. They were grouped as follows, and presented in alphabetical order:

Group I included items receiving 24 or more votes, including the following:

- Arterial switch operation

- Blalock-Taussig shunt (Blalock, Taussig, and Thomas)

- Cardiopulmonary bypass

- Echocardiographic imaging (including foetal echocardiography)

- Fontan/Kreutzer procedure and subsequent modifications

- Dr William Norwood and the Norwood Procedure

- Rashkind atrial septostomy

- Prostaglandin

Group 2 included items receiving 15-21 votes, including the following:

- Dr Robert Anderson (nomenclature and anatomic concepts)
- Dr Philipp Bonhoeffer and transcatheter pulmonary valve replacement (over all other interventional catheter procedures)

- Cardiac critical care as a discipline

- Computer technology

- Databases (STS, PHYS, PC4, IMPACT)

- Digitisation of cardiac images

- Electronic health records

- Foetal echocardiography

- Interventional catheterisation, including atrial septal defect closure, persistent ductus arteriosus closure, balloon valvotomy, all types of balloon dilations, and all types of stents

- Mustard and Senning procedures

- Persistent ductus arteriosus ligation

- Dr Richard and Dr Stella Van Praagh (nomenclature and anatomic concepts)

Group 3 included items receiving 10-14 votes, including the following:

- Ablation of accessory pathways

- Cardiac catheterisation for haemodynamics and angiography

- Cardiac MRI and CT

- Cardiac transplantation

- Coarctation repair (Dr Clarence Crafoord)

- Cross-circulation for support in cardiac surgery

- Dr Aldo Castaneda

- Dr C. Walton Lillehei's multiple contributions

- Extracorporeal membrane oxygenation

- Implantable cardiac pacemakers and defibrillators

- Genetics and genomics and the secondary heart field

- Nitric oxide

- Surgery for the neonate (early correction of CHD)

- Ventricular assist devices, especially Berlin Heart

Group 4 included items receiving five to nine votes, including the following:

- Adult CHD as a discipline

- Dr Kurt Amplatz

- Dr Leonard Bailey

- Cardioplegia

- Channelopathies

- Deep hypothermic circulatory arrest

- Dr Marc de Leval

- Electrocardiography

- Dr Paul Gillette

- Heparin

- Implementation of clinical trials in CHD (various)

- Dr James Lock

- Mechanical and biological prosthetic heart valves

- Dr Alexander Nadas

- "Natural History Study" of CHD

- Neurodevelopmental outcome analysis

- Paediatric cardiac nursing as a discipline

- Pulmonary hypertension management 
- Dr Giancarlo Rastelli (the Rastelli operation and right ventricle to pulmonary artery conduits)

- Sir Donald Ross and the pulmonary autograft procedure

- Sir William Harvey

- Stem cells in heart disease

- Transoesophageal echocardiography

An additional 215 items received at least one vote. The categories of nomination, speaking broadly, can be grouped as follows: individuals (9), operations (8), specific types of interventional cardiologic procedures (7), medications (4), technology (7), imaging (6), organisation of care (4), nomenclature (1), support systems for surgery (4), concepts (3), basic science (4), and clinical outcome research (2).

Finally, during the 2017 WCPCCS, the organisers - including Jeffrey P. Jacobs, Gil Wernovsky, Mitchell Cohen, and David Cooper - of the 2021 WCPCCS to be held from September 19 to 24, 2021, in Washington, DC, United States of America (www. WCPCCS2021.org), presented a timeline of important events in the history of congenital and paediatric cardiac care, which can be found as Figure 1. A color version of the timeline is available at WCPCCS2021.org

\section{Discussion}

Many of the attendees of the Congress have expressed an interest in obtaining a copy of the presentation, so the authors, in conjunction with Cardiology in the Young, have decided to make the entire work available (Fig 2). The presentation is protected by international copyright but can be freely used for academic and educational purposes. Permission to reproduce any of the material in the presentation can be requested from the authors. The slide show is reproduced here in the exact format presented at the WCPCCS in Barcelona.

\section{Conclusion}

There appears to be considerable interest in our heritage, as evidenced by the number of recent requests for this presentation, as well as the interest expressed during the WCPCCS for both access to the presentation and copies of the timeline. The task of ordering events by their importance is clearly subjective and probably impossible to complete in a simple survey of this type. We clearly recognise the importance of many other people, technologies, procedures, disciplines, and much more. These contributions constitute the "shoulders of giants" on which we currently stand. Nonetheless, it is particularly interesting to note the diversity of responses from what could be considered a rather homogeneous group of paediatric cardiac practitioners. The authors hope, however, that the responses will be thought provoking, and a tribute to those who have contributed in ways that we will continue to recognise and honour. 
Timeline created for the 2021 WCPCCS exhibit in Barcelona

$1600 \mathrm{~s}$

De Motu Cordis (Harvey)

Rheumatic fever described (Sydenham)

1800s

Stethoscope (Laennec)

Anesthesia

Measured cardiac ouput (Fick)

Tetralogy described (Fallot)

Transposition described (Baille)

The Principals \& Practices of Medicine (Osler)

$\mathrm{X}$-Ray imaging discovered (Roentgen)

Cardiac surgery for stab wounds

Discovery of protamine

Artificial ventilation described

First children's hospital (Hôpital des Enfants Malades, Paris))

$1900 s-1950 s$

Electrocardiography (Einthoven)

Atlas of Congenital Heart Disease (Abbott)

Discovery of heparin

Endotracheal intubation and mechanical ventilation

Cardiac catheterization

Persistent ductus arteriosus ligation

Isolation of digoxin from foxglove

Mechanisms of pulmonary hypertension described

Hypoplastic left heart syndrome described

Preventative cardiology

Wolff-Parkinson-White arrhythmia

Coarctation repair (Crafoord)

Blalock-Taussig shunt (Blalock, Taussig, Thomas)

Battery operated Pacemaker (Bakken)

AC defibrillation (Zoll)

First implantable pacemaker (Senning)

Atrial septectomy (Blalock and Hanlon)

Waterston shunt

Potts Shunt

Pulmonary valvotomy (Brock)

Pulmonary arterial band

Cross-circulation (Lillehei)

Open heart surgery with cardiopulmonary bypass (Dennis and others)

Senning operation

Glenn shunt

Pulse oximetry

Clinical use of coumadin (warfarin)

Sudden cardiac death described

Penicillin for rheumatic fever

Figure 1.

Timeline of Pediatric and Congenital Cardiac Care, prepared by the organisers - including Jeffrey P. Jacobs, MD, Gil Wernovsky, Mitchell Cohen, and David Cooper - of the 2021 WCPCCS to be held from 19 to 24 September, 2021, in Washington, DC, United States of America (www. WCPCCS2021.org). 


\section{0s}

Transvenous pacemakers

Dedicated cardiac ICU (adult)

Cardiopulmonary resuscitation described

Description of fetal circulation

Mustard operation

Morphologic descriptions of congenital heart disease

Natural History Study 1

Long QT syndrome described

Rashkind procedure

Transcatheter closure of ductus arteriosus (Portsmann)

Kawasaki disease described

Fontan and Kreutzer right heart bypass

Di George syndrome described

Rastelli operation

Amiodarone introduced

Closed mitral commissurotomy

Ventricular assist device (DeBakey)

Pulmonary autograft aortic valve replacement (Ross)

Lung transplantation

Surgical ablation of WPW

Transvenous defibrillation

Heart transplantation

\section{0s}

Polytetrafluroethylene (Gore-tex) for clinical use

Transesophageal echocardiography

Prostaglandin E1

Transcatheter ASD closure (King)

Extracorporeal membrane oxygenation

Arterial switch for TGA/VSD (Jatene)

High frequency oscillatory ventilation

Adult congenital heart disease/Grown up congenital heart disease specialty

Percutaneous coronary intervention

Electrophysiologic mapping

Expansion of clinical applications of genetics/genomics

Total parenteral nutrition

Gamma globulin for Kawasaki disease

Cyclosporine introduced

Pediatric intensive care

Transesophageal echocardiography

Norwood Procedure

Neonatal arterial switch operation

\section{0s}

Ablation for arrhythmia in adults

Implantable cardiac defibrillator (trans-thoracic and trans-venous)

Heart lung transplantation

Natural History Study 2

Transcatheter pulmonary valvotomy (Kan)

Xenotransplantation (Bailey)

Pediatric cardiac intensive care

Pulmonary artery angioplasty

Balloon expandable vascular stents

Recognition and study of developmental disabilities in cardiac patients 
Boston Circulatory Arrest Trial

Nitric oxide

Total cavopulmonary connection (de Leval)

Indomethacin for ductal closure

Society of Thoracic Surgeons Database

Fetal cardiac intervention

Extracardiac Fontan (Marcelletti et al)

Focalization of pulmonary arteries in infants

World Congresses: London, New York, Bergamo, Bangkok

\section{0s}

Ablation for arrhythmia in children

Primacorp trial (milrinone)

Amplatzer atrial septal defect closure

ABO incompatible heart transplantation

Cardiac MRI evolves

Expansion of databases and registries

Palivizumab trial

Adenosine for supraventricular tachycardia

Radiofrequency ablation for arrhythmia treatment

Berlin Heart VAD development

Electronic medical records

Telemedicine

Tissue engineering for cardiac implants

World Congresses: Paris, Honolulu

\section{0s}

Fetal cardiac catheter intervention

Transcatheter pulmonary valve replacement (Bonhoeffer)

Hybrid surgical strategy for hypoplastic left heart syndrome

IMPACT Registry

Single Ventricle Reconstruction trial

Transcatheter aortic valve implantation

Carvedilol Trial

Home inter-stage monitoring following palliation for HLHS

Robotic Surgery

Channelopathies and sudden cardiac death

Public reporting of surgical outcomes

World Congresses: Buenos Aires, Cairns

\section{0s}

Pediatric Critical Care Consortium

3D printing for congenital heart imaging

Stem cell trials in heart disease

MAP-IT Registry

National Pediatric Cardiology Quality Improvement Collaborative

Fetal Cardiac Intervention Registry

Genetic link of CHD and neurodevelopment (Pediatric Heart Network)

World Congresses: Cape Town, Barcelona

\section{0s}

8th World Congress of Pediatric Cardiology and Cardiac Surgery,

To be held September 19-24, 2021, Washington D.C. 
$7^{\text {th }}$ WORLD CONGRESS OF

PEDIATRIC CARDIOLOGY \& CARDIAC SURGERY 16-21 JULY, 2017 •BARCELONA

\begin{tabular}{|c|c|c|c|}
\hline & & \multicolumn{2}{|c|}{ Cardiology + Intensive Care $(n=28)$} \\
\hline \multicolumn{2}{|c|}{ Surgery $(n=20)$} & Robert Beekman & Jan Marek \\
\hline Leonard Bailey & Viktor Hraska & Stuart Berger & Ornella Milanesi \\
\hline Emre Belli & Hajime Ichikawa & Damien Bonnet & Douglas Moodie \\
\hline Ed Bove & Krishna lyer & Robert Campbell & Jane Newburger \\
\hline Sertaç Çiçek & Jeff Jacobs & John Cheatham & Daniel Penny \\
\hline Joe Dearani & Richard Jonas & Mitchell Cohen & Carlos Ruiz \\
\hline Yves D'Udekem & Tom Karl & Ziyad Hijazi & Shak Qureshi \\
\hline Roberto DiDonato & Rick Ohve & Chris Hugo-Hamman & Robert Shaddy \\
\hline Tianc & 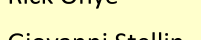 & Pavarthi Iyer & Gary Sholler \\
\hline IJark Ebels & Giovanni Stellin & Jan Janousek & Norman Silverman \\
\hline Martin Elliott & Jim Tweddell & Krishna Kumar & Ed Walsh \\
\hline Jose Fragata & Bill Williams & Peter Laussen & Gary Webb \\
\hline & & Michael Landzberg & Gil Wernovsky \\
\hline
\end{tabular}

\begin{tabular}{|c|c|c|c|}
\hline & & \multicolumn{2}{|c|}{ Cardiology + Intensive Care $(n=28)$} \\
\hline \multicolumn{2}{|c|}{ Surgery $(n=20)$} & Robert Beekman & Jan Marek \\
\hline Leonard Bailey & Viktor Hraska & Stuart Berger & Ornella Milanesi \\
\hline Emre Belli & Hajime Ichikawa & Damien Bonnet & Douglas Moodie \\
\hline Ed Bove & Krishna lyer & Robert Campbell & Jane Newburger \\
\hline Sertaç Çiçek & Jeff Jacobs & John Cheatham & Daniel Penny \\
\hline Joe Dearani & Richard Jonas & Mitchell Cohen & Carlos Ruiz \\
\hline Yves D'Udekem & Tom Karl & Ziyad Hijazi & Shak Qureshi \\
\hline Roberto DiDonato & Rick Ohve & Chris Hugo-Hamman & Robert Shaddy \\
\hline Tianc & 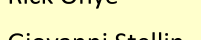 & Pavarthi Iyer & Gary Sholler \\
\hline IJark Ebels & Giovanni Stellin & Jan Janousek & Norman Silverman \\
\hline Martin Elliott & Jim Tweddell & Krishna Kumar & Ed Walsh \\
\hline Jose Fragata & Bill Williams & Peter Laussen & Gary Webb \\
\hline & & Michael Landzberg & Gil Wernovsky \\
\hline
\end{tabular}

Important Events in Pediatric Cardiology and Congenital Heart Surgery

\begin{tabular}{|} 
Thanks to the Survey \\
Respondents Who Chose \\
The Events, People, \\
Technologies and Therapies \\
Shown In These Slides \\
\multicolumn{3}{c|}{ Respondents From: } \\
Australia & Namibia \\
Canada & Netherlands \\
Dubai & Portugal \\
France & Qatar \\
Germany & South Africa \\
India & Turkey \\
Italy & United Kingdom \\
Japan & USA
\end{tabular}

Figure 2.

Slide show presentation displayed at the 2017 Seventh World Congress of Pediatric Cardiology E Cardiac Surgery (WCPCCS 2017), Barcelona, Spain.

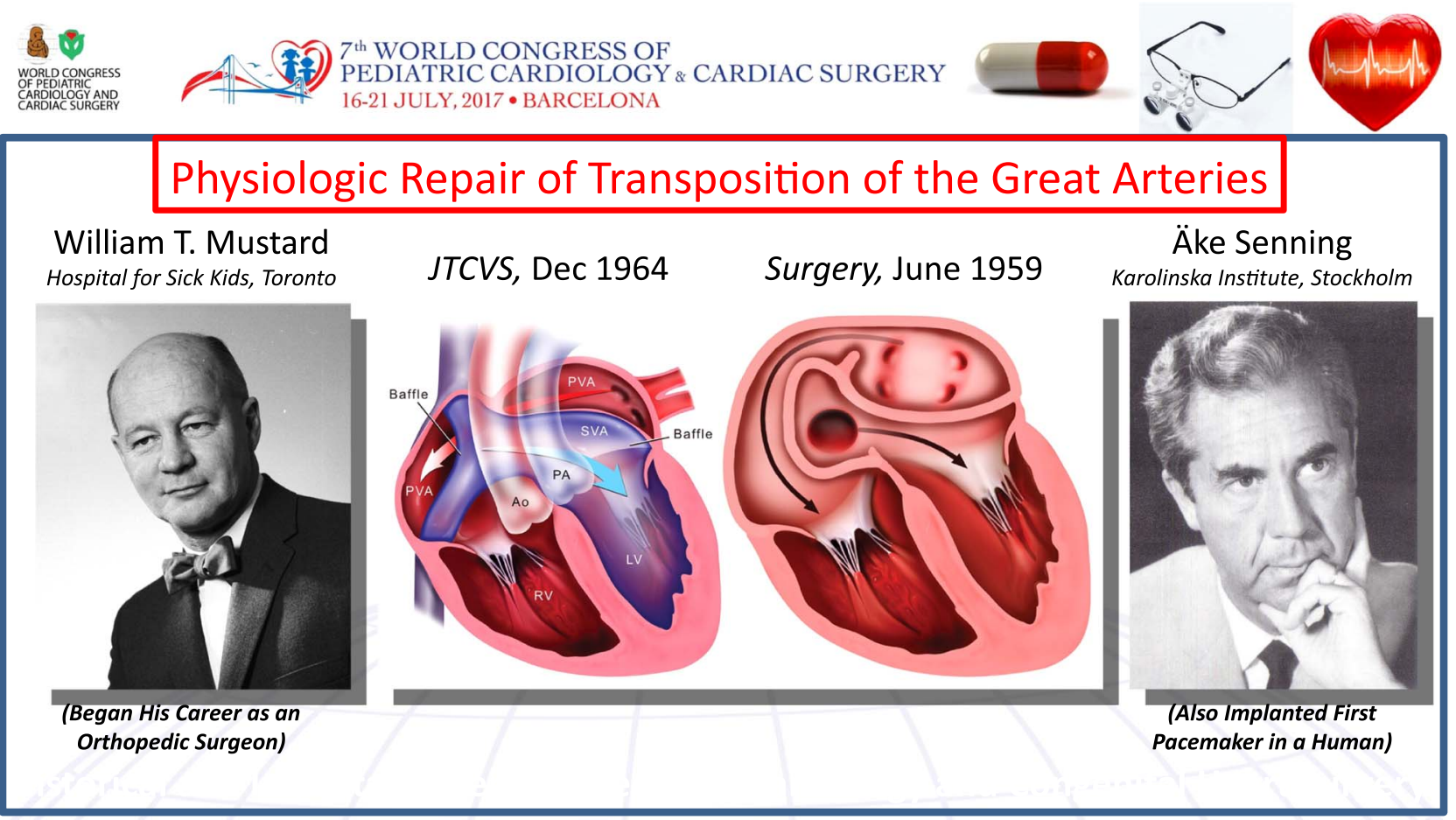


2) $7^{\text {th }}$ WORLD CONGRESS OF

PEDIATRIC CARDIOLOGY \& CARDIAC SURGERY

16-21 JULY, 2017 • BARCELONA

Dr. William I. Norwood

Norwood WI, Kirklin JK, Sanders SP.

Hypoplastic left heart syndrome: experience

with palliative surgery. Am J Cardiol 1980;45:87-91.

This is a report of a new palliative procedure for HLHS that has resulted in early ongoing survival of two infants with aortic atresia. On the basis of experience with a third patient, an operation for future physiologic correction is proposed.
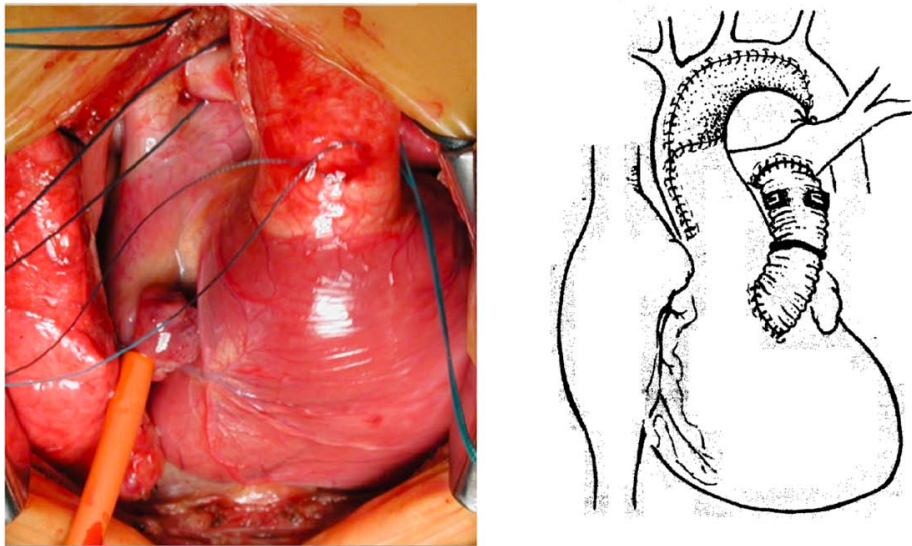

Boston-Philadelphia-Genolier-Wilmington

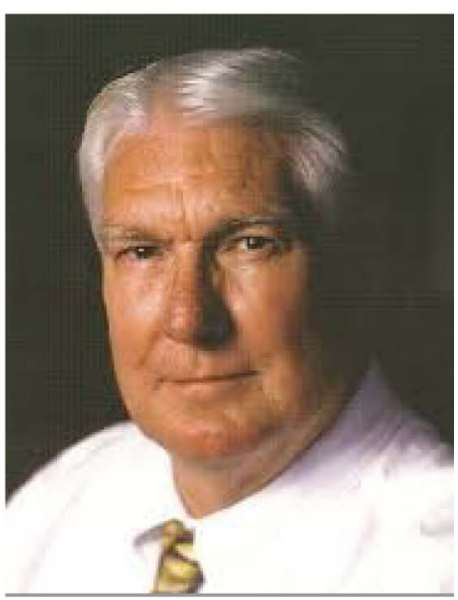

Surgery for HLHS
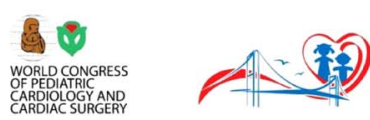

$7^{\text {th }}$ WORLD CONGRESS OF

PEDIATRIC CARDIOLOGY \& CARDIAC SURGERY 16-21 JULY, 2017 • BARCELONA

\footnotetext{
- Increasing Use in:

- Peripheral pulmonary arteries

- Systemic and pulmonary veins

- Aorta and branches

- Conduits

- Arterial duct

- Aortopulmonary shunts

- Intracardiac communications.
}

\section{Implantable Stents}
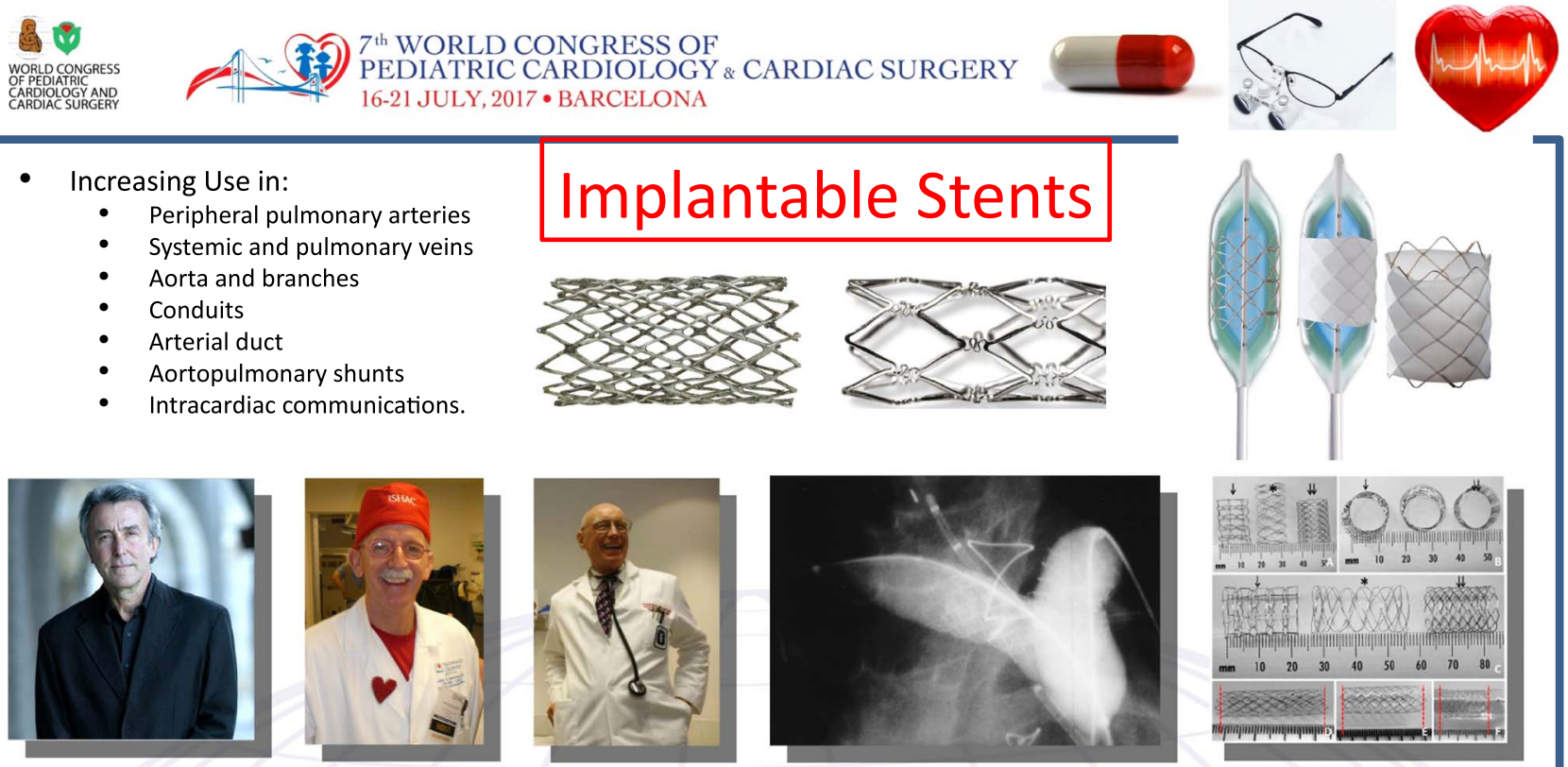

Julio Palmaz John Cheatham

Charles Mullins

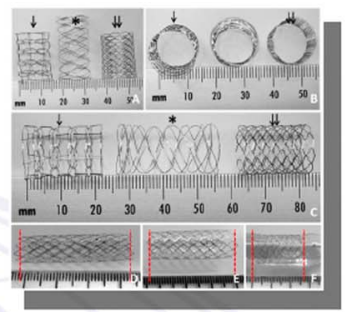

(continued) 
(1) $7^{\text {th }}$ WORLD CONGRESS OF

PEDIATRIC CARDIOLOGY \& CARDIAC SURGERY 16-21 JULY, 2017 • BARCELONA
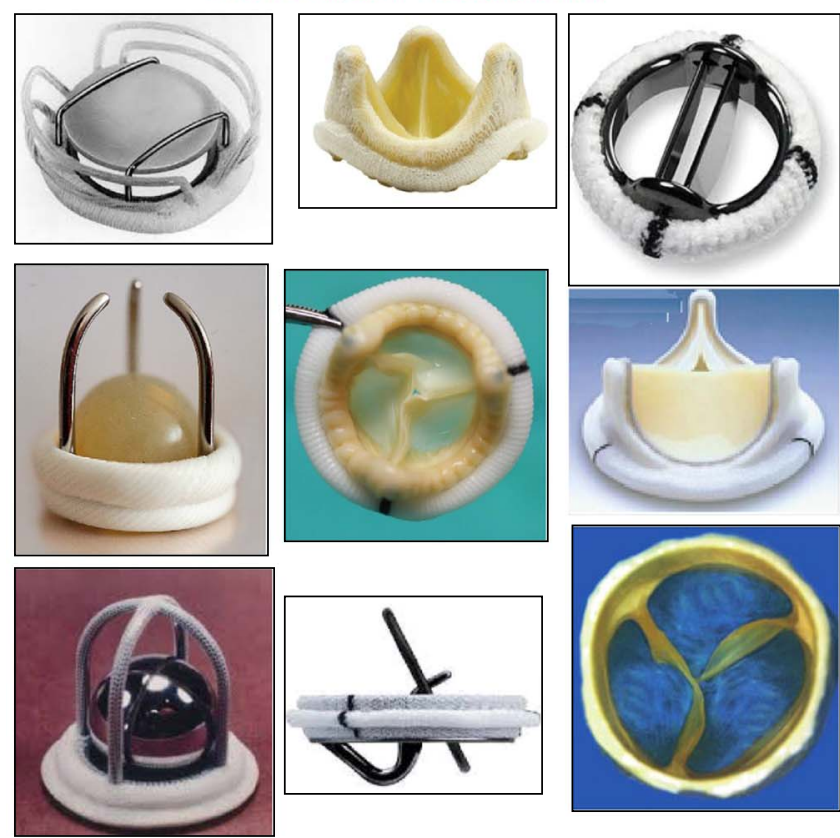
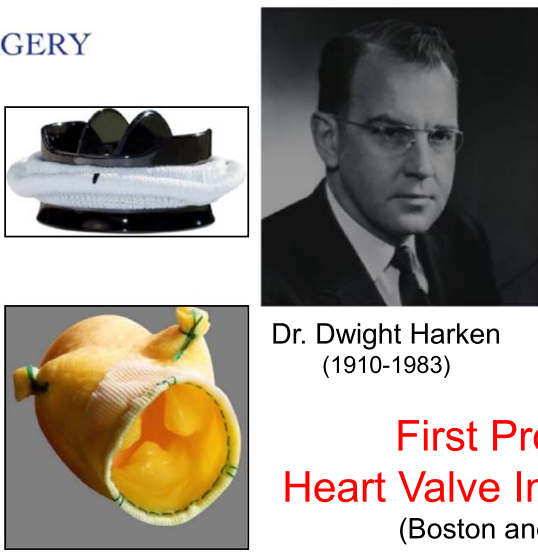

Dr. Dwight Harken (1910-1983)

First Prosthetic

Heart Valve Implants, 1960

(Boston and Portland)

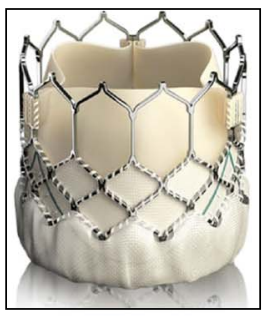

Harken mitral valve (29 year implant!)

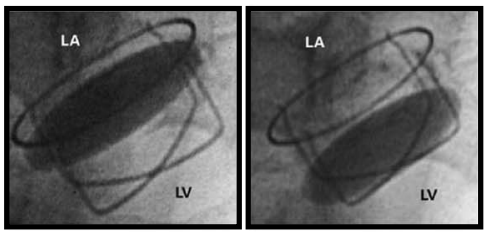

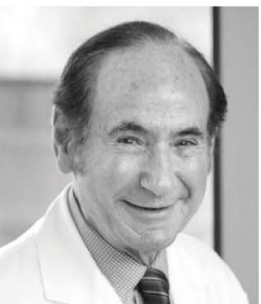

Dr. Albert Starr

7. $7^{\text {th }}$ WORLD CONGRESS OF

PEDIATRIC CARDIOLOGY \& CARDIAC SURGERY 16-21 JULY, $2017 \bullet$ BARCELONA
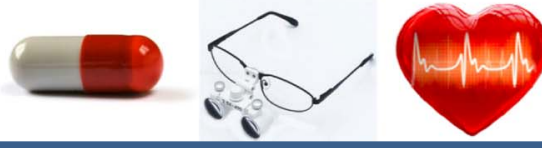

Evolution and Specialization of Cardiac Nursing and Pediatric Cardiac Intensive Care

Developed synergistically with technology and neonatal surgery for complex congenital cardiac disease First physically and administratively separate unit in Boston in late 1970's

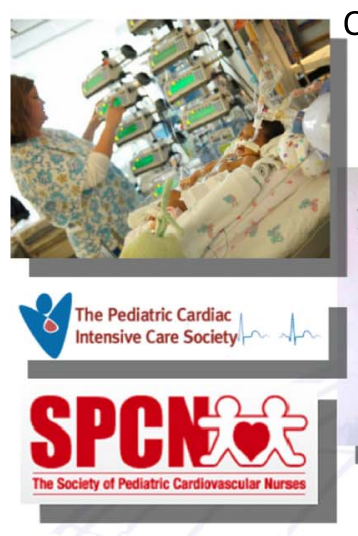

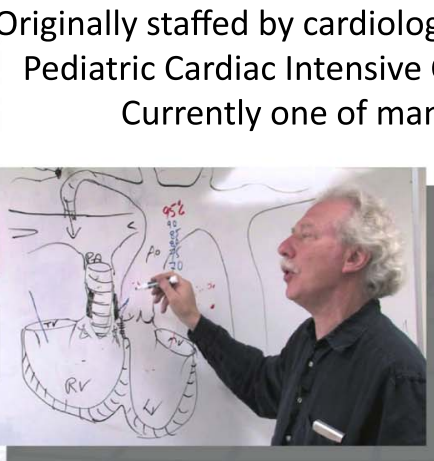

Peter Lang
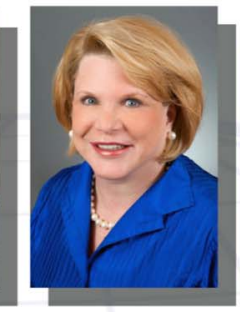

Patricia Hickey

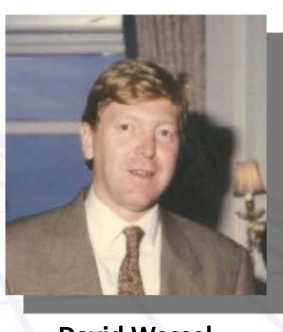

David Wessel

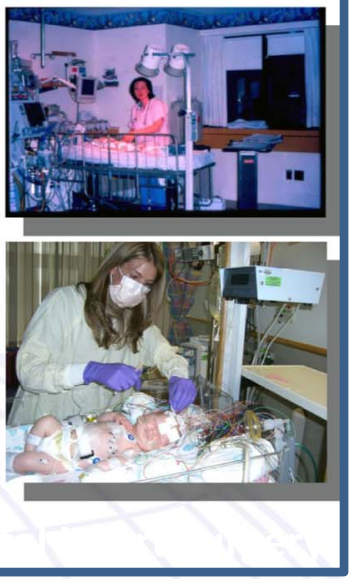




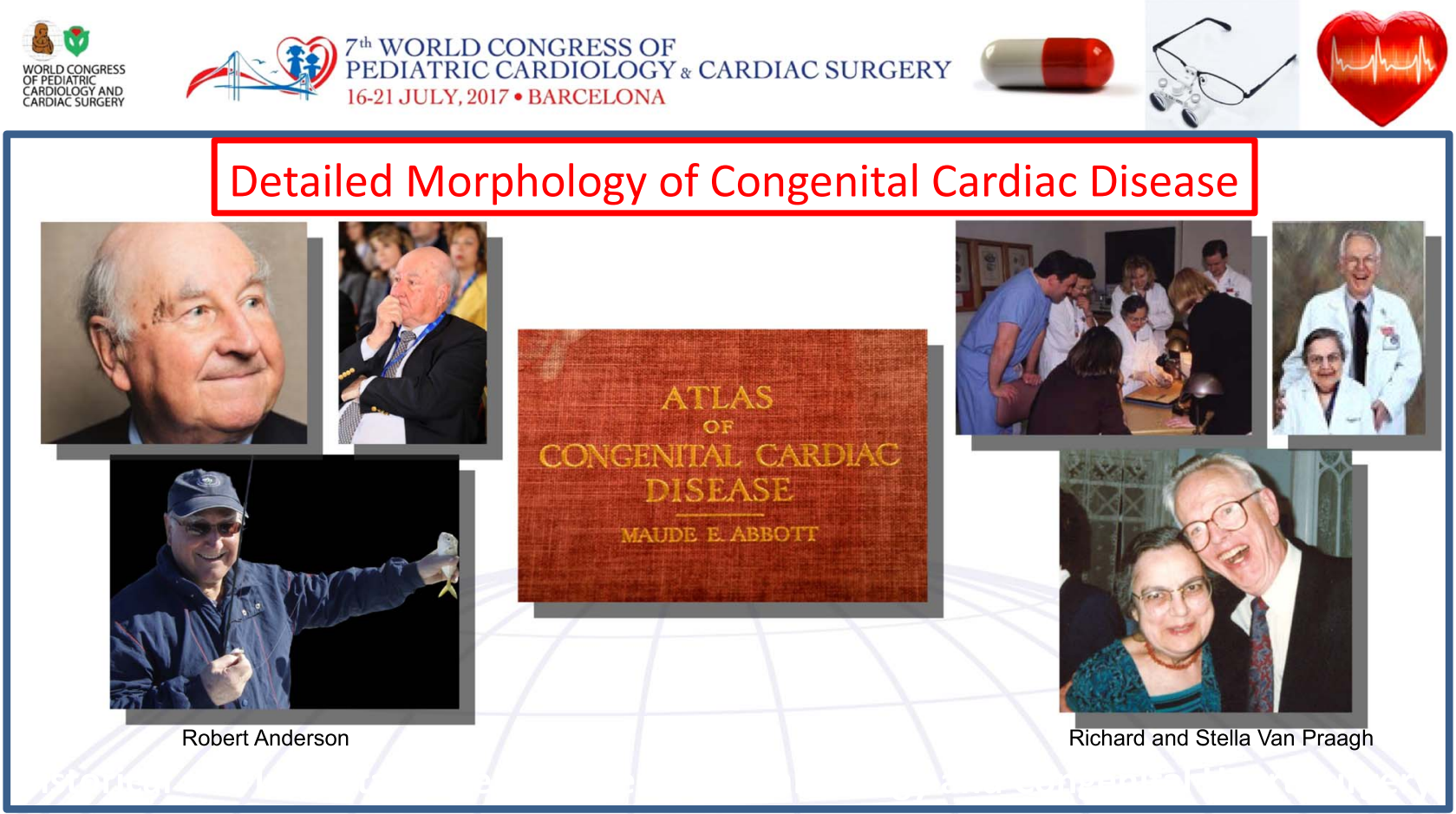

$7^{\text {th }}$ WORLD CONGRESS OF PEDIATRIC CARDIOLOGY \& CARDIAC SURGERY 16-21 JULY, $2017 \bullet$ BARCELONA

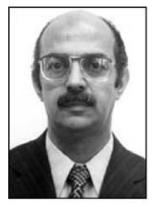

\section{Arterial Switch Operation 1975}

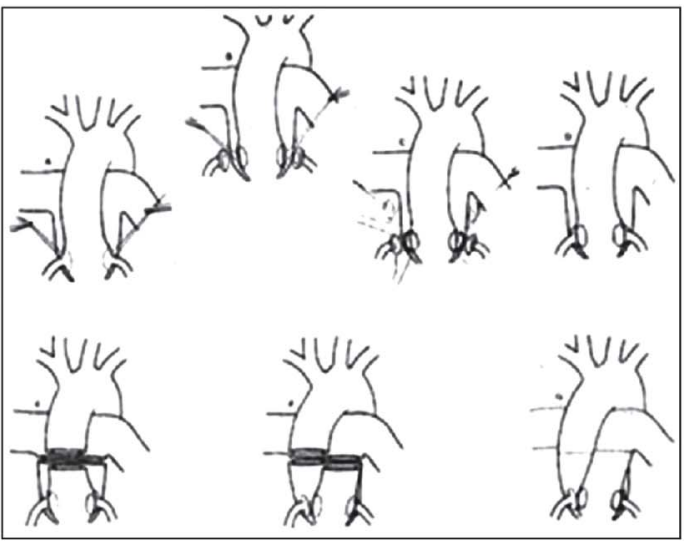

Jatene AD, Fontes VF, Paulista PP, de Souza LC, Neger F, Galantier $M$, Souza JE. Successful anatomic correction of transposition of the great vessels. A preliminary report. Arq Bras Cardiol 1975;28:461-64. Dr. Adib Jatene (1929-2014)
São Paulo, Brasil

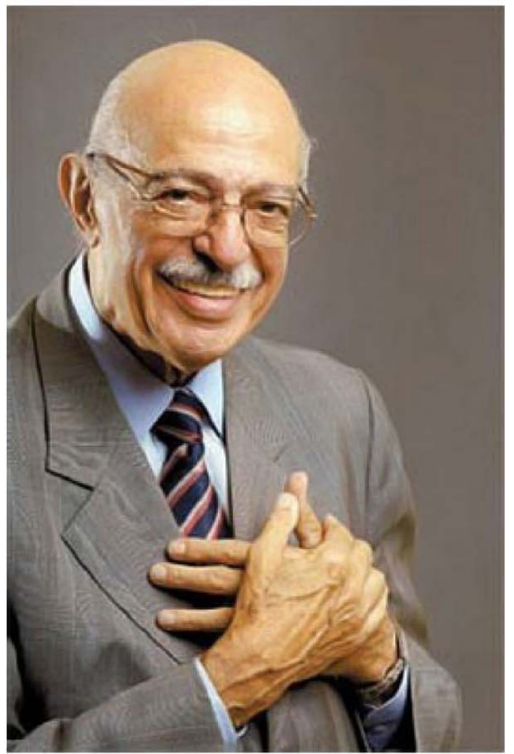



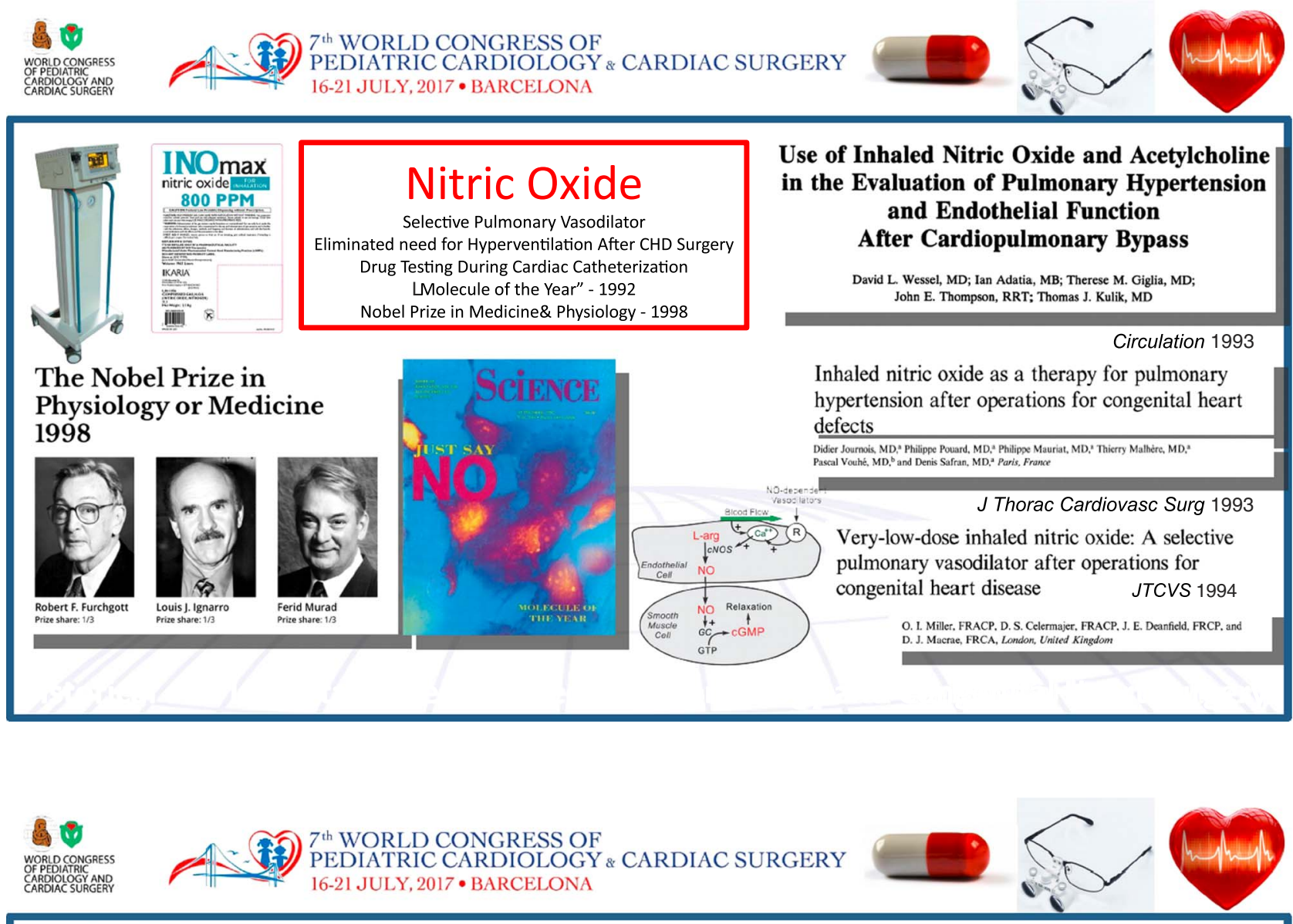

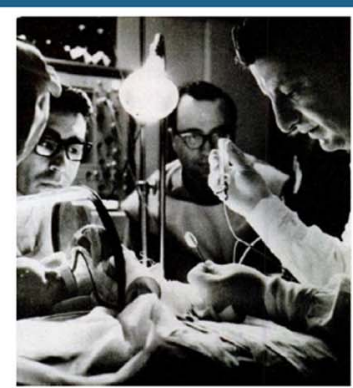

Life Magazine May 27, 1966

A standby repair until surgery
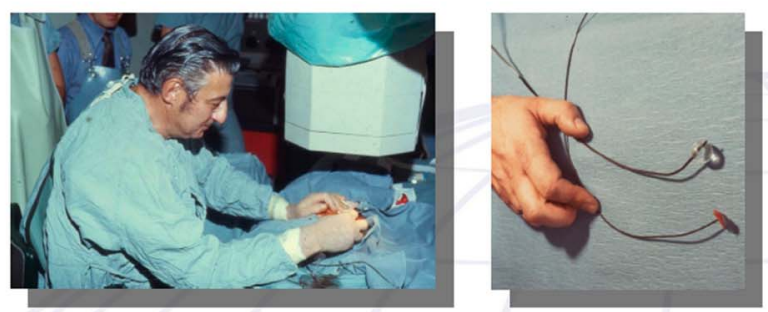

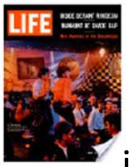

\section{William J. Rashkind}

Reported $1^{\text {st }}$ Balloon Atrial Septostomy in a neonate ("Bobby") in Life Magazine (and then in JAMA 1 month later)

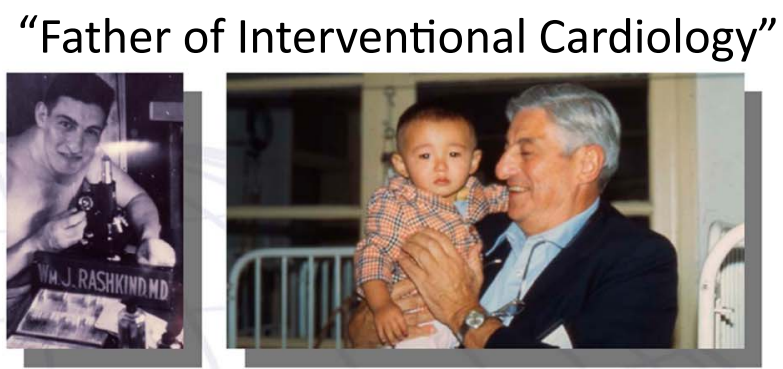



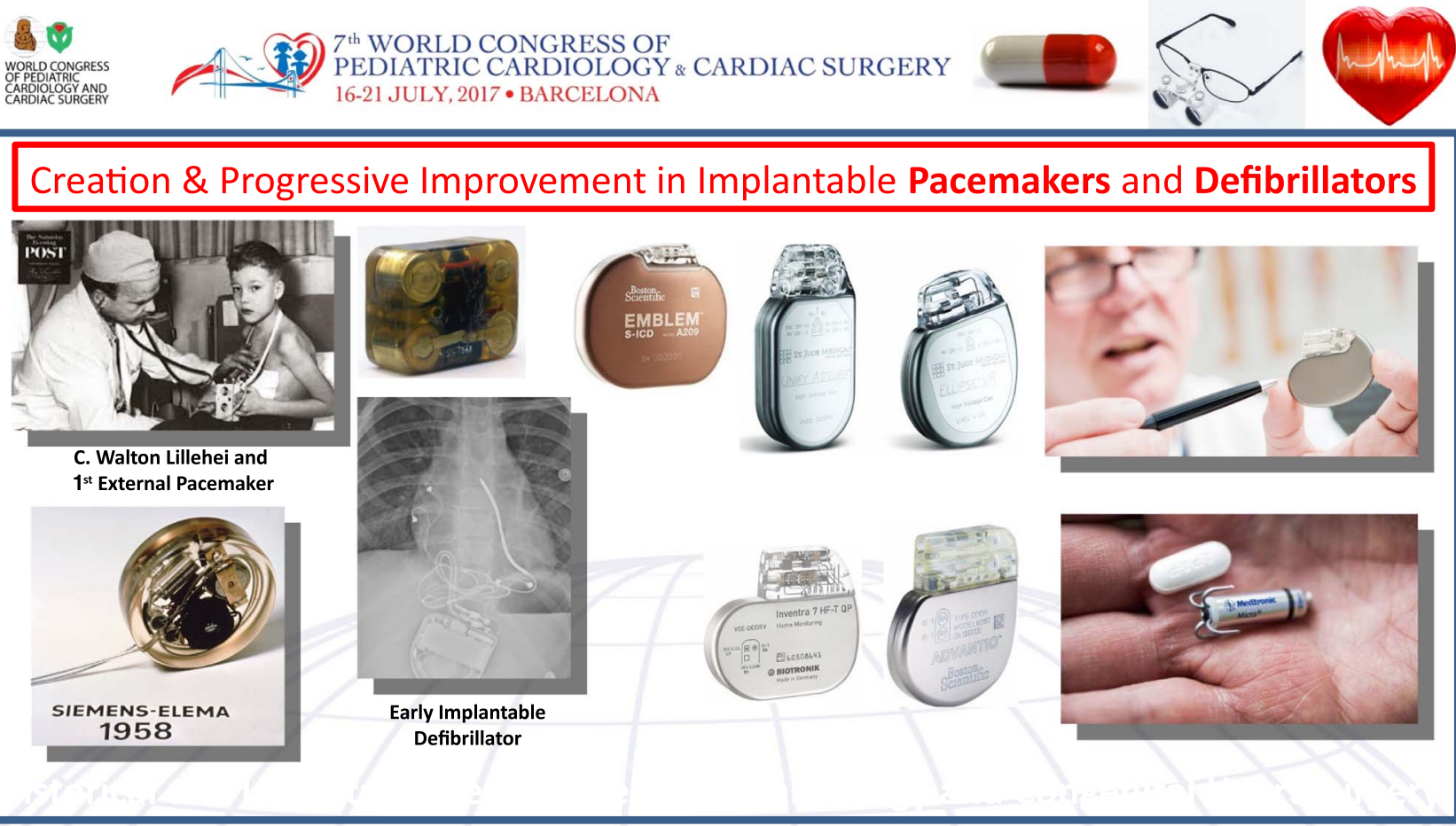

웅
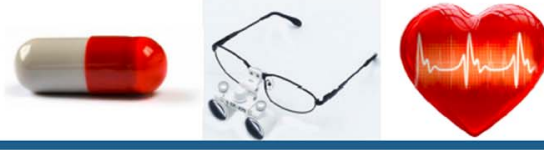

The Rise of Genetics and Genomics in Understanding Congenital Heart Disease

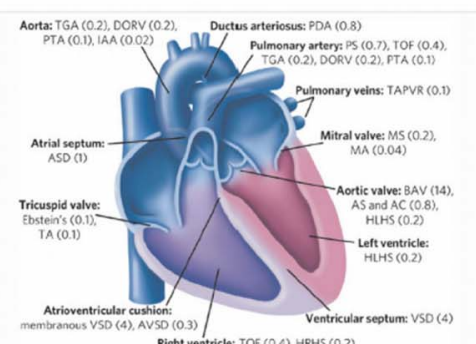

The developmental genetics of congenital heart disease Benoit G. Bruneau

(2008) doi: $10.1038 /$ nature06801

\section{nature}

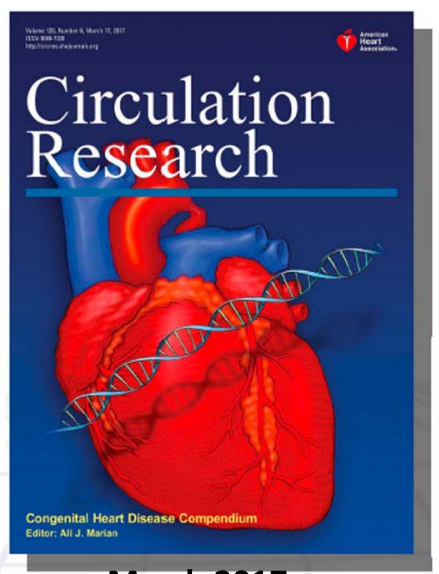

March 2017
Distinct genetic architectures for syndromic and nonsyndromic congenital heart defects identified by exome sequencing

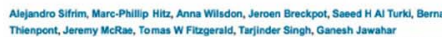

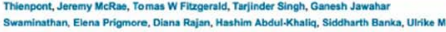

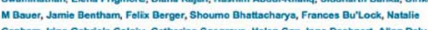
Cannartit.

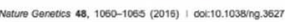
nature
genetics

Genetics and Genomics of Congenital Heart Disease Samir Zaidi, Martina Brueckner

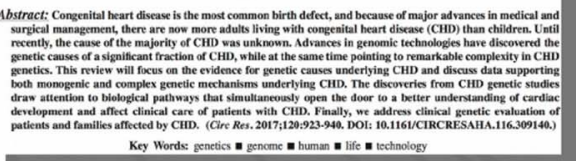

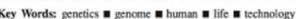



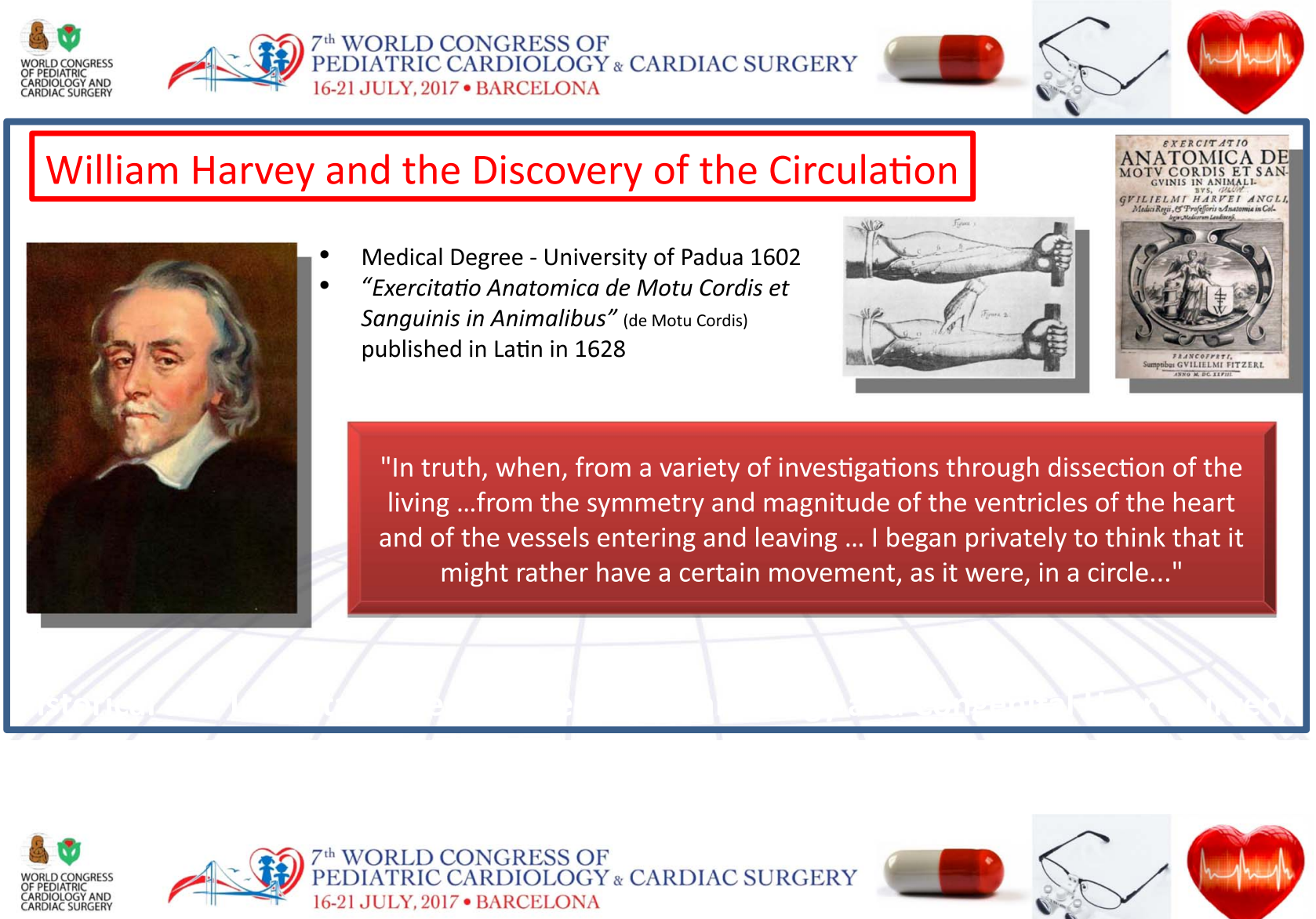

$7^{\text {th }}$ WORLD CONGRESS OF

PEDIATRIC CARDIOLOGY \& CARDIAC SURGERY 16-21 JULY, $2017 \bullet$ BARCELONA
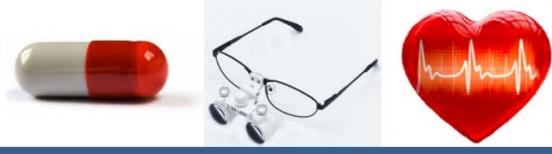

\section{Paul C. Gillette 1943-2013}

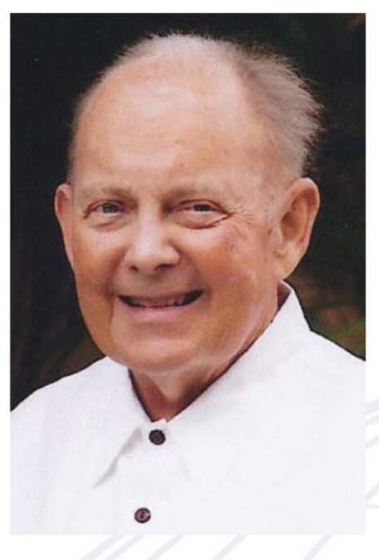

- Pediatric Residency and Cardiology Fellowship at Texas Children's Hospital and Baylor College of Medicine

- American Academy of Pediatrics

- 1975 - Young Investigator Award

- 1982-83- Chair of Section on Cardiology

- 2009 Founder's Award

- 1998 - Pioneer in Pacing and Electrophysiology Award from the Heart Rhythm Society

- 2013 - Lifetime Achievement Award from The Pediatric and Congenital Electrophysiology Society

- Over 300 Peer-Reviewed publications

- Huge NASCA - exas Motor Speedway

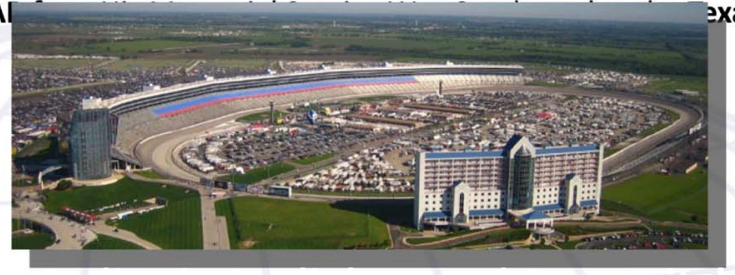



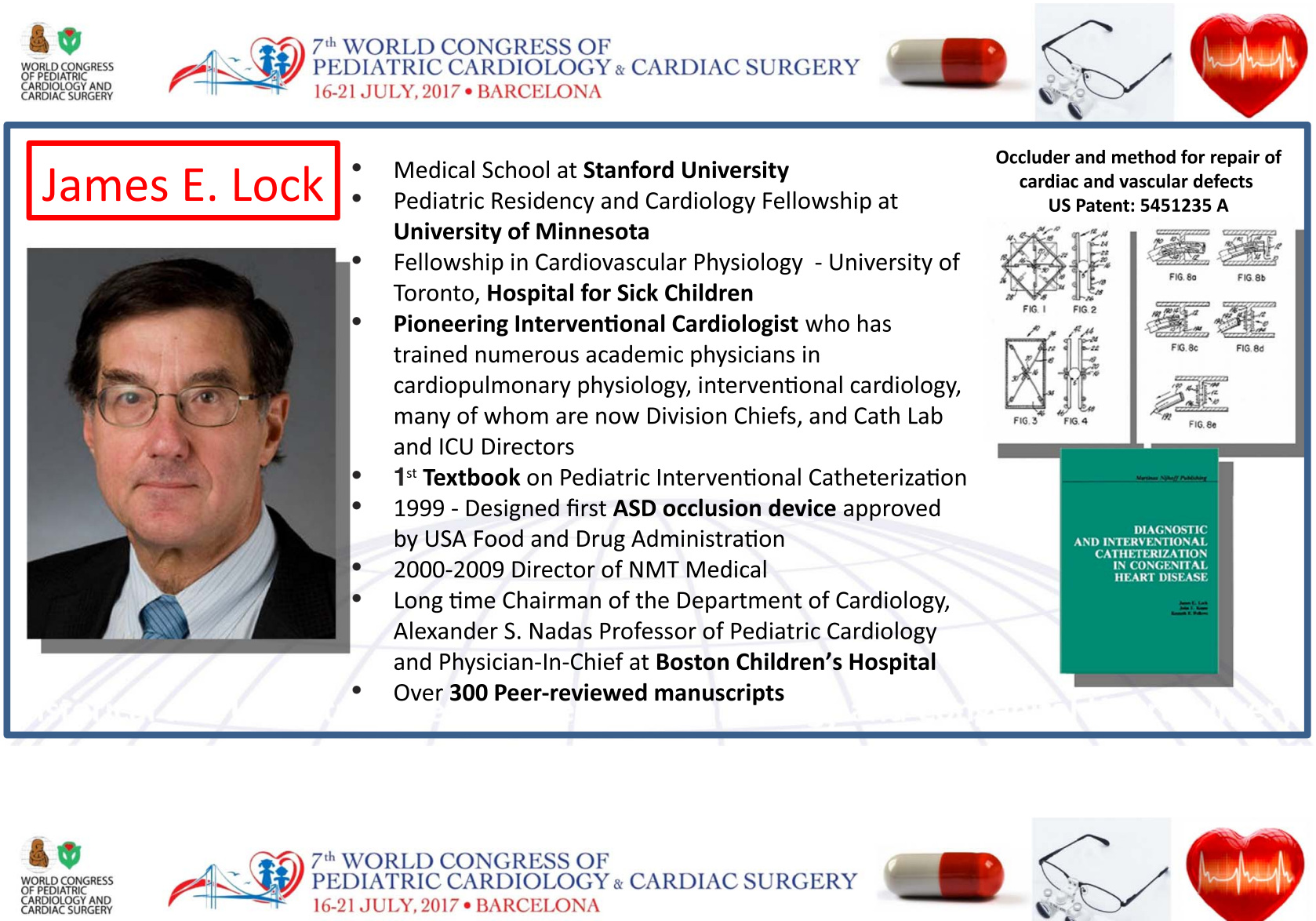

$7^{\text {th }}$ WORLD CONGRESS OF PEDIATRIC CARDIOLOGY \& CARDIAC SURGERY 16-21 JULY, $2017 \bullet$ BARCELONA
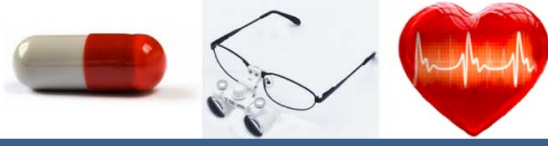

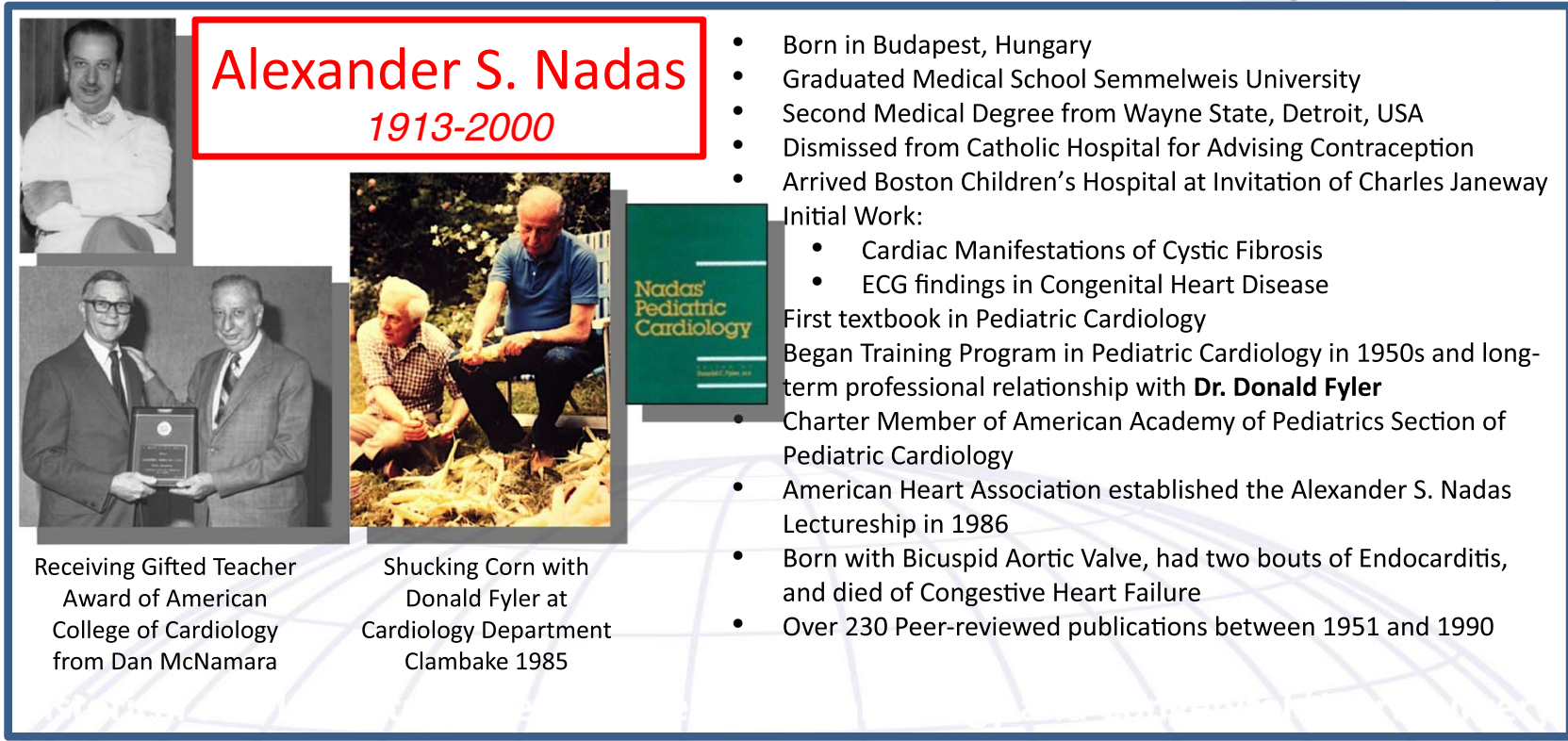




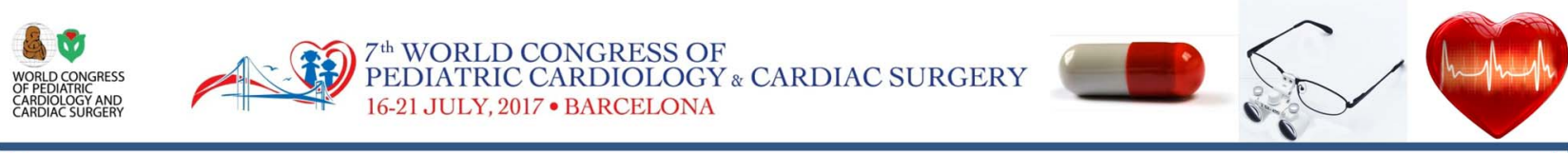

\begin{tabular}{|c|c|c|}
\hline 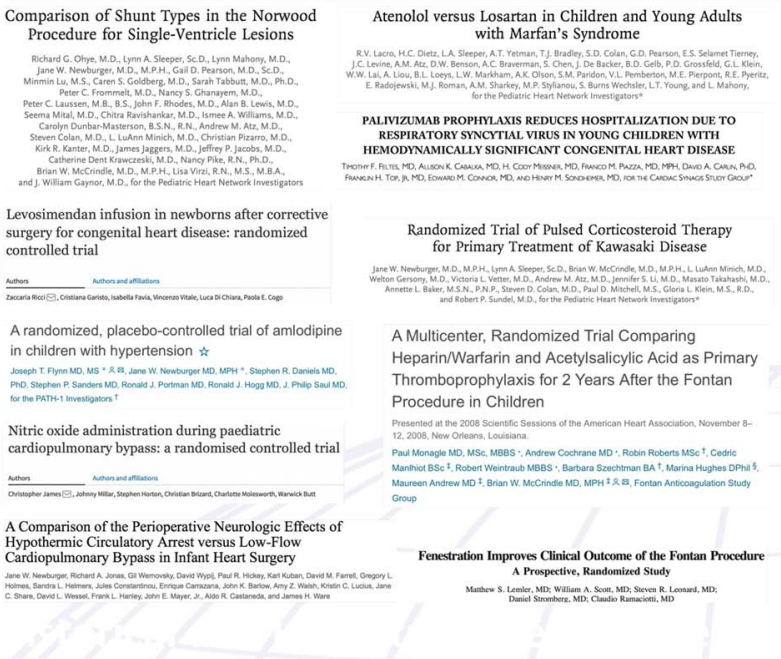 & 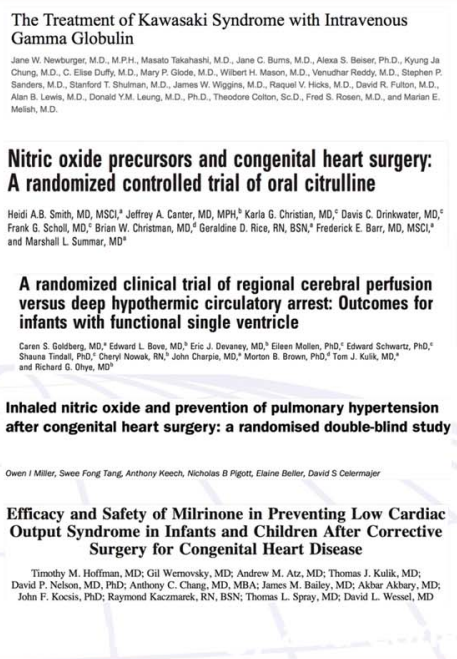 & 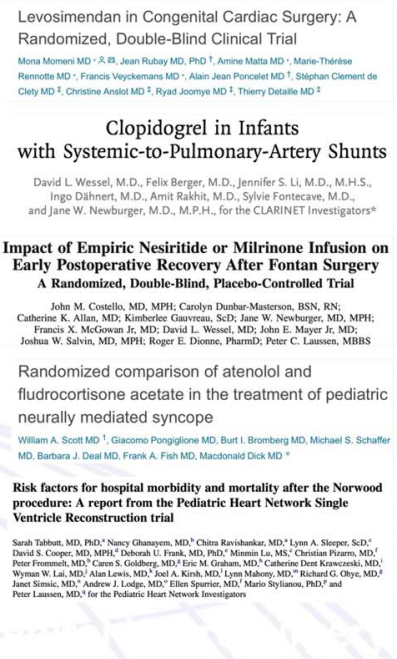 \\
\hline
\end{tabular}
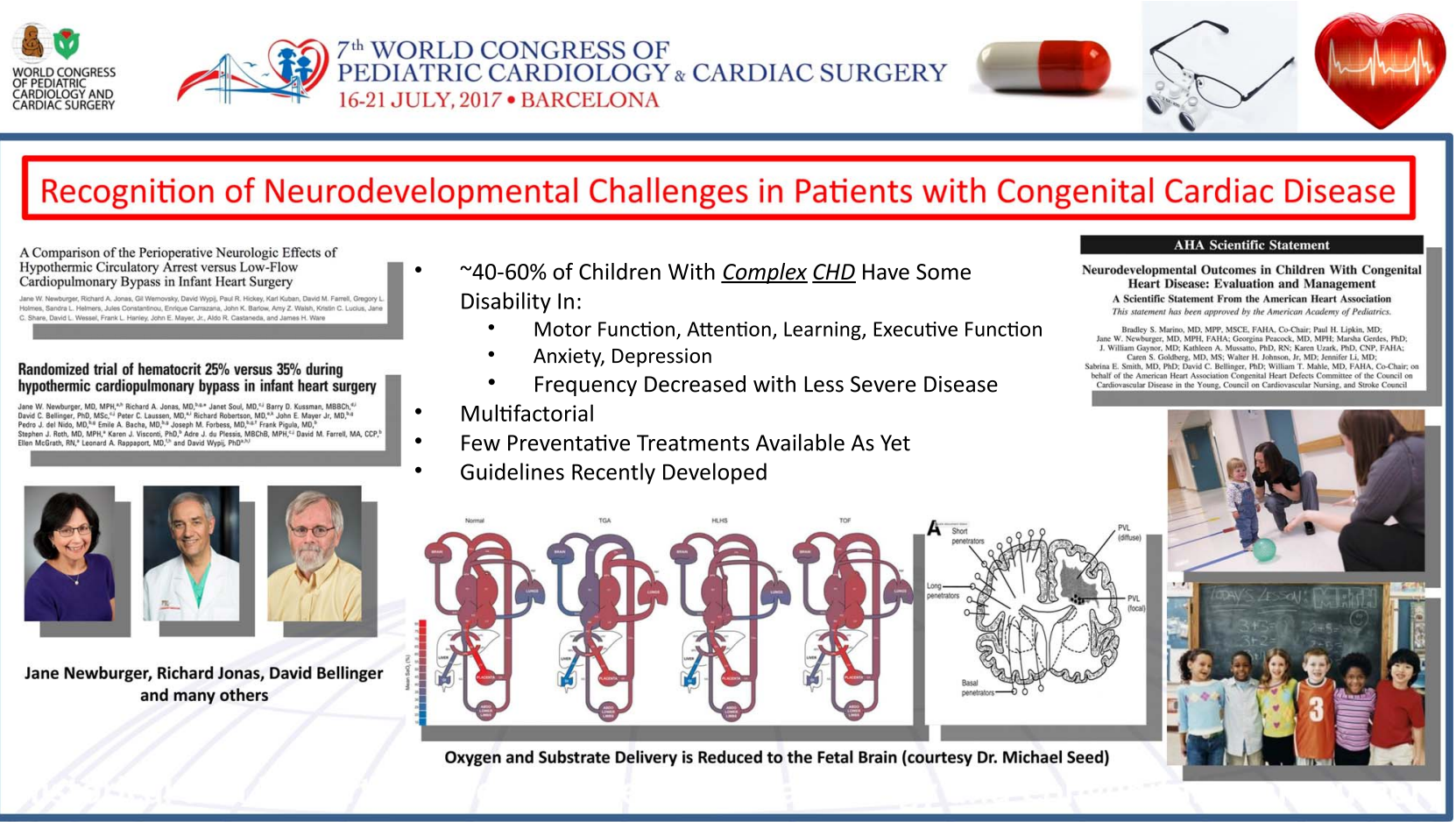

(continued) 


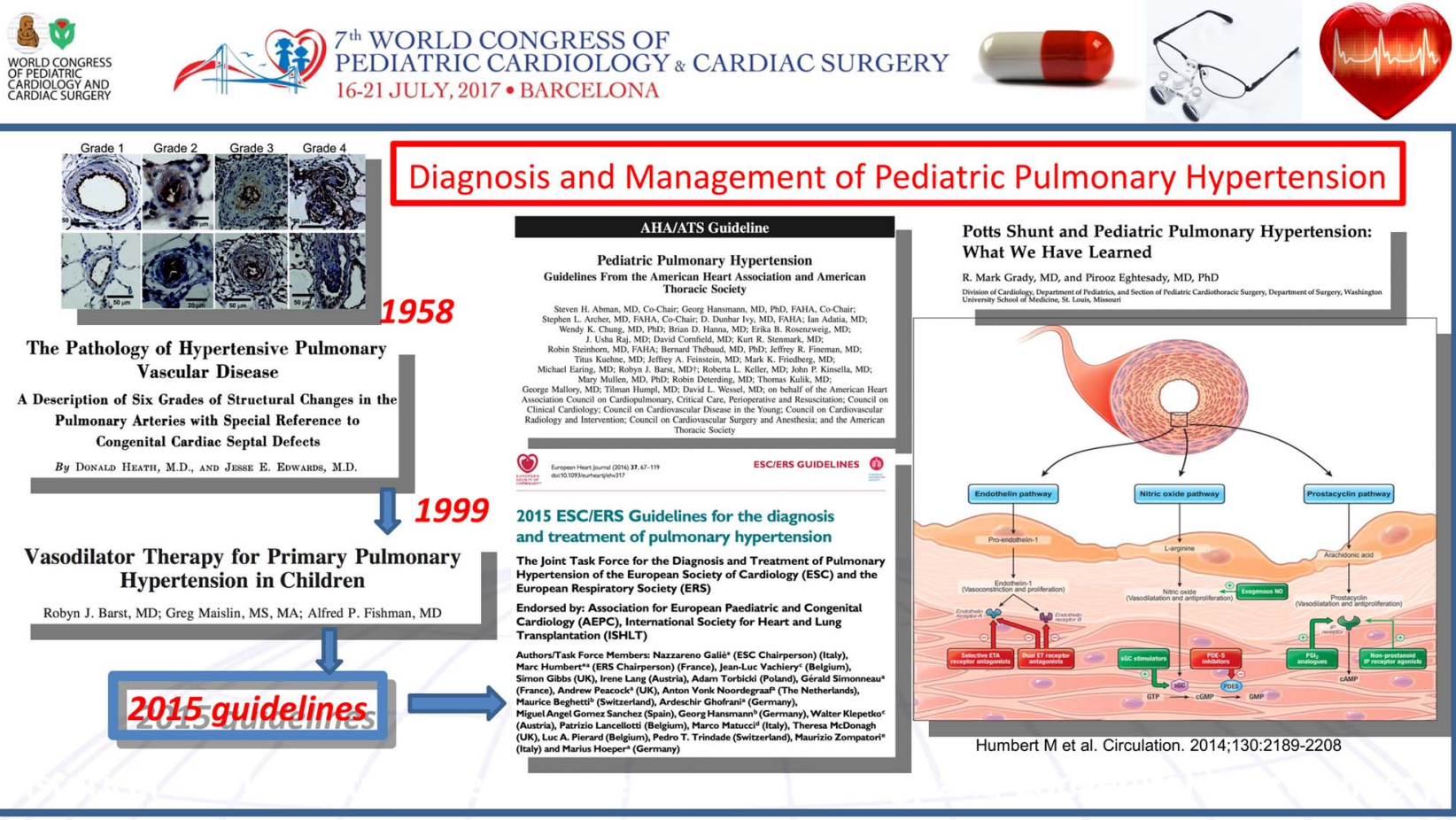

\section{6} WopLCOCNGRES

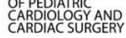

\section{A (90) $7^{\text {th }}$ WORLD CONGRESS OF PEDIATRIC CARDIOLOGY \& CARDIAC SURGERY 16-21 JULY, 2017 • BARCELONA}
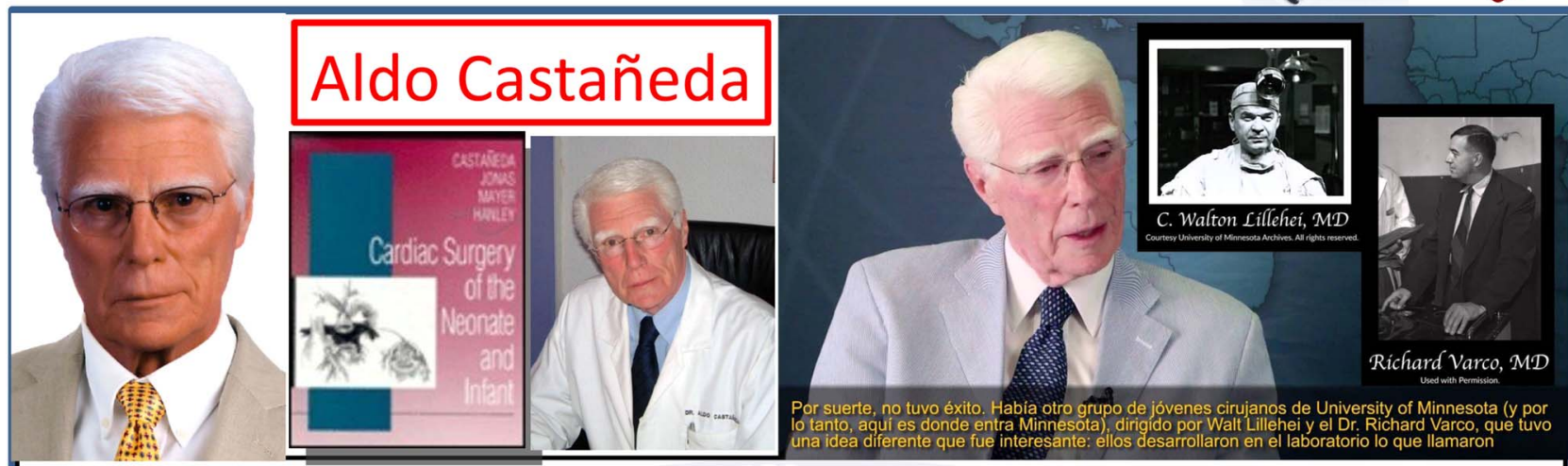

- University of Guatemala Medical School

- Surgical and cardiothoracic residencies at the University of Minnesota (which at the time [1950s] was performing the world's first open heart surgeries)

- 1972: Recruited to Boston Children's Hospital in 1972

- Chief of Cardiovascular surgery and Surgeon-in-Chief at Boston Children's Hospital for 24 years

- Pioneer of neonatal cardiac surgery

- 1983: Helped pioneer the arterial switch operation for transposition of the great arteries

- Trained a generation of pediatric cardiac surgeons 


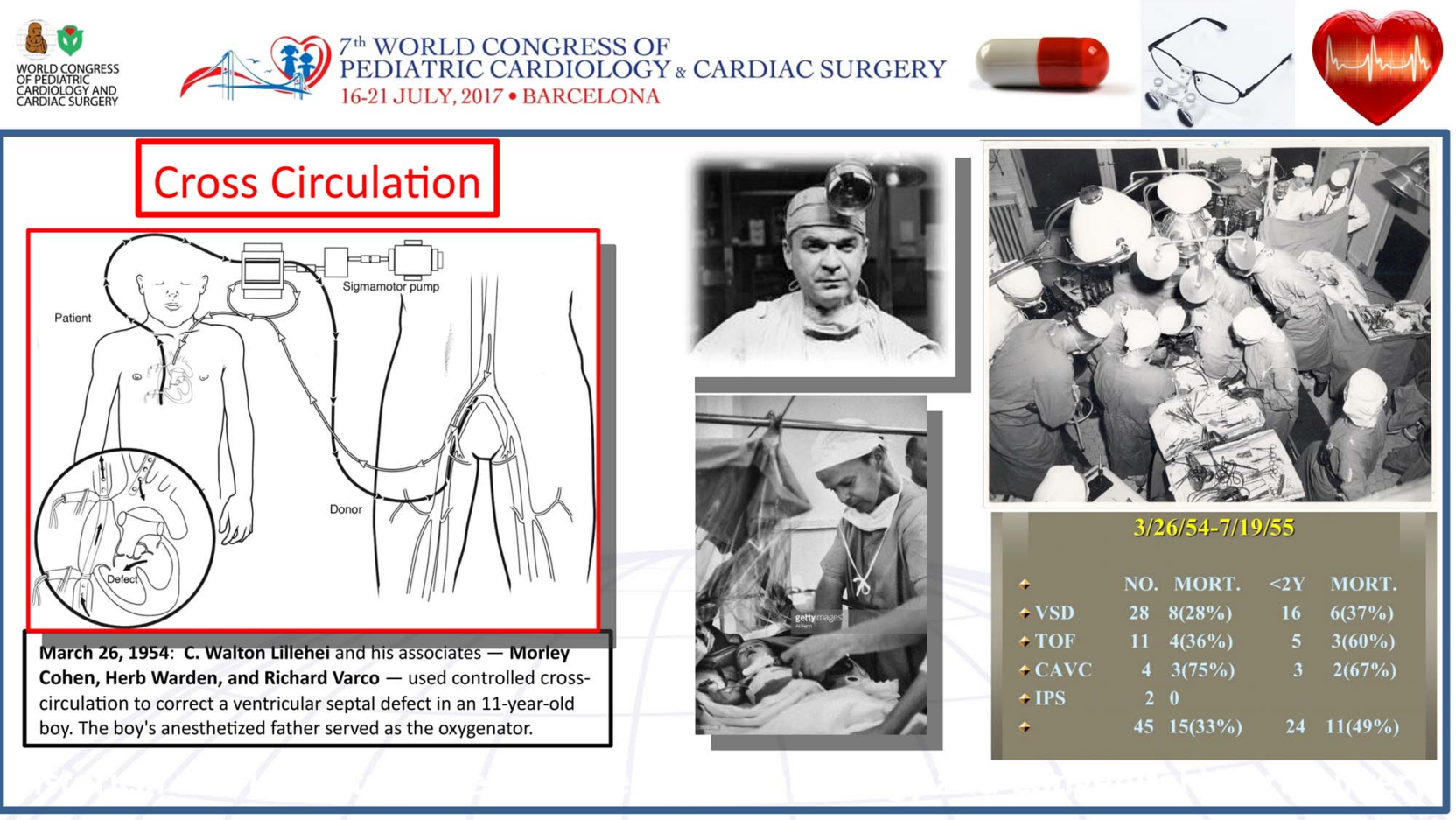

8 WORLC CONGRESS OF PEDIATAC ANS
CARDOACGAND
CARDIACSURGERY

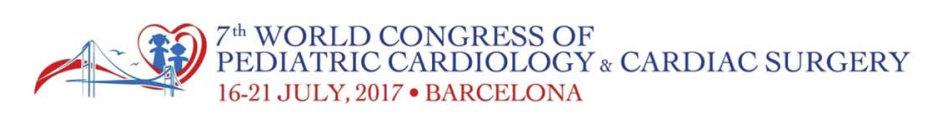
PEDIATRIC CARDIOLOGY \& CARDIAC SURGERY 16-21 JULY, 2017 • BARCELONA

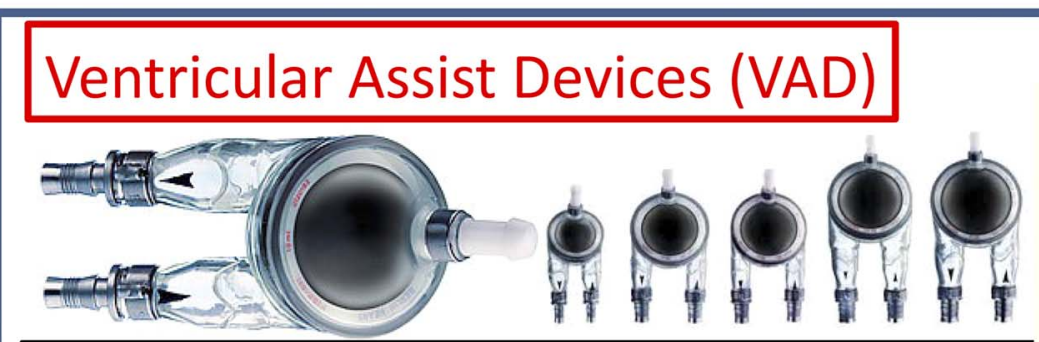

\section{Berlin Heart}

1996: The EXCOR Stationary Driving Unit Ikus received CE approval.

1999: The EXCOR mobile driving unit received CE approval.

2000: The first child in the USA is supported by EXCOR Pediatric.

2003: INCOR received CE approval after successfully completing the Multi-Center Study.

2008: The INCOR patient Jean-Pierre Offe celebrated his five-year anniversary while on the system and therefore setting an INCOR world record.

2008: EXCOR Pediatric received unrestricted IDE Approval in the USA.

2009: The 500th patient received INCOR VAD at the German Heart Institute.

2011: EXCOR Pediatric received FDA approval for the U.S. market. The number of children who had been on EXCOR Pediatric reached over 1,000.

2012: The longest support time of a toddler on EXCOR Pediatric reached 2.5 years.

2013: The EXCOR Pediatric $15 \mathrm{ml}$ blood pump received CE approval.

2014: The 1,500th pediatric patient was supported by EXCOR Pediatric. 
$7^{\text {th }}$ WORLD CONGRESS OF

PEDIATRIC CARDIOLOGY \& CARDIAC SURGERY 16-21 JULY, $2017 \bullet$ BARCELONA

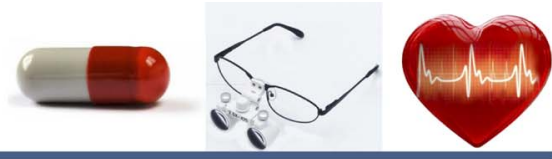

\section{ExtraCorporeal Membrane Oxygenation (ECMO)}

- Developed during the 1960 s and 1970 s

- Robert Bartlett, MD (a surgeon at the University of Michigan) and his colleagues pioneered the clinical use of ECMO in newborns with respiratory failure

- Bartlett reported the first neonatal survivor of ECMO, referred to as Baby Esperanza, in 1976. Baby Esperanza suffered lung damage from meconium aspiration syndrome. ECMO was applied as a last-ditch effort to save her life. The baby spent three days on Bartlett's machine and survived.
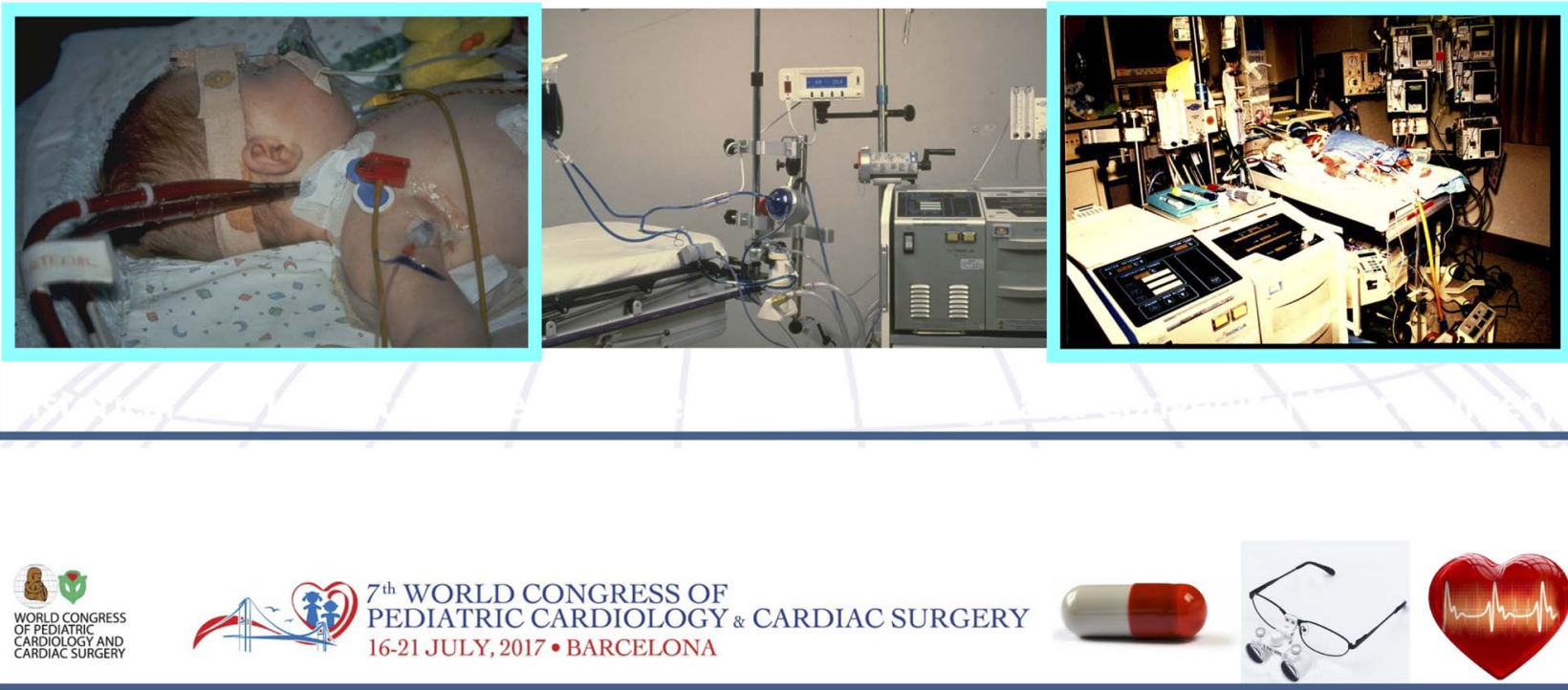

\section{Deep Hypothermic Circulatory Arrest}

Deep hypothermic circulatory arrest is a surgical technique that involves cooling the body to temperatures below $20^{\circ} \mathrm{C}\left(68^{\circ} \mathrm{F}\right)$, stopping the circulation and greatly reducing brain metabolism
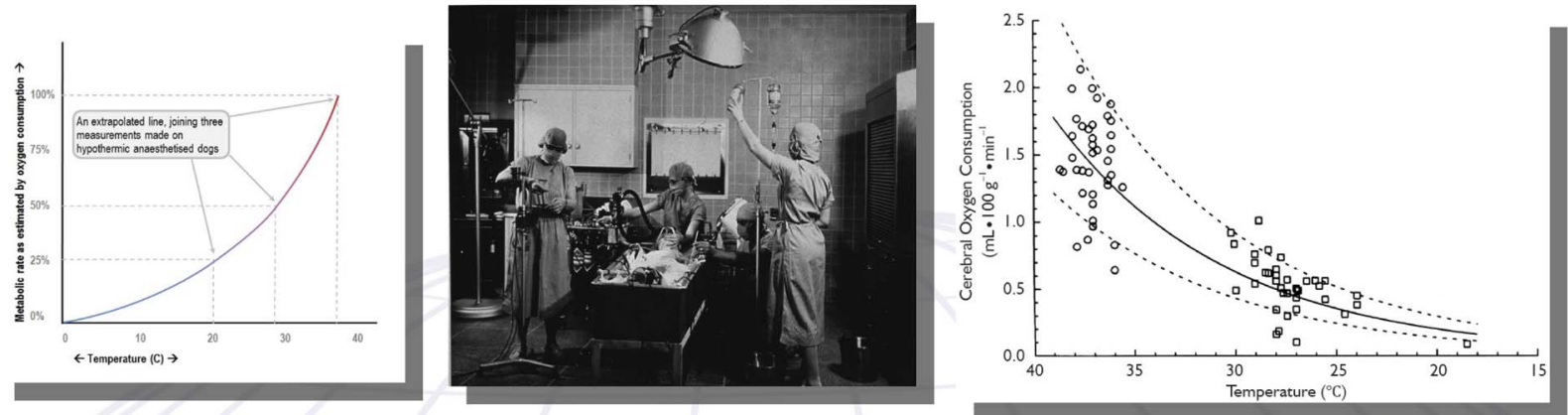

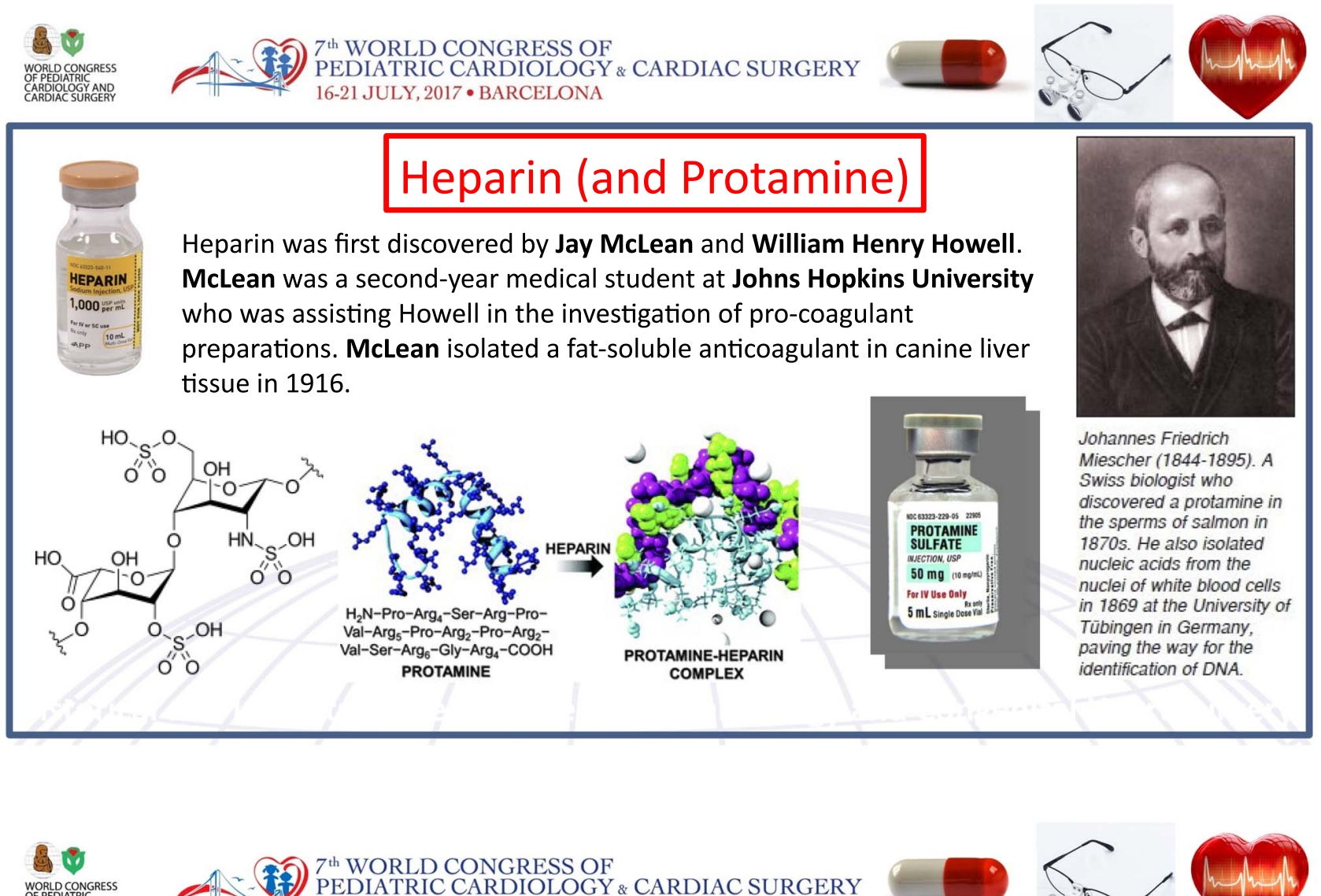

$7^{\text {th }}$ WORLD CONGRESS OF

PEDIATRIC CARDIOLOGY \& CARDIAC SURGERY 16-21 JULY, 2017 • BARCELONA

\section{Cardioplegia}

THE LANCET] [JULY 2, 1955

\section{CONCLUSIONS}

Cardiac arrest in diastole inevitably results from an injection of potassium citrate into the root of the aorta so that the bulk of it enters the coronary arteries.

D. G. Melrose

M.A., B.M. Oxfd

B. DREYER

Department of Surgers, M.D. Cape Town, F.R.C.S. of London

H. H. Bentali

M.B. Lond., F.R.C.S

Department of Physiology, school, London

J. B. E. BAKER M.A., B.Se., B.M. Oxfd
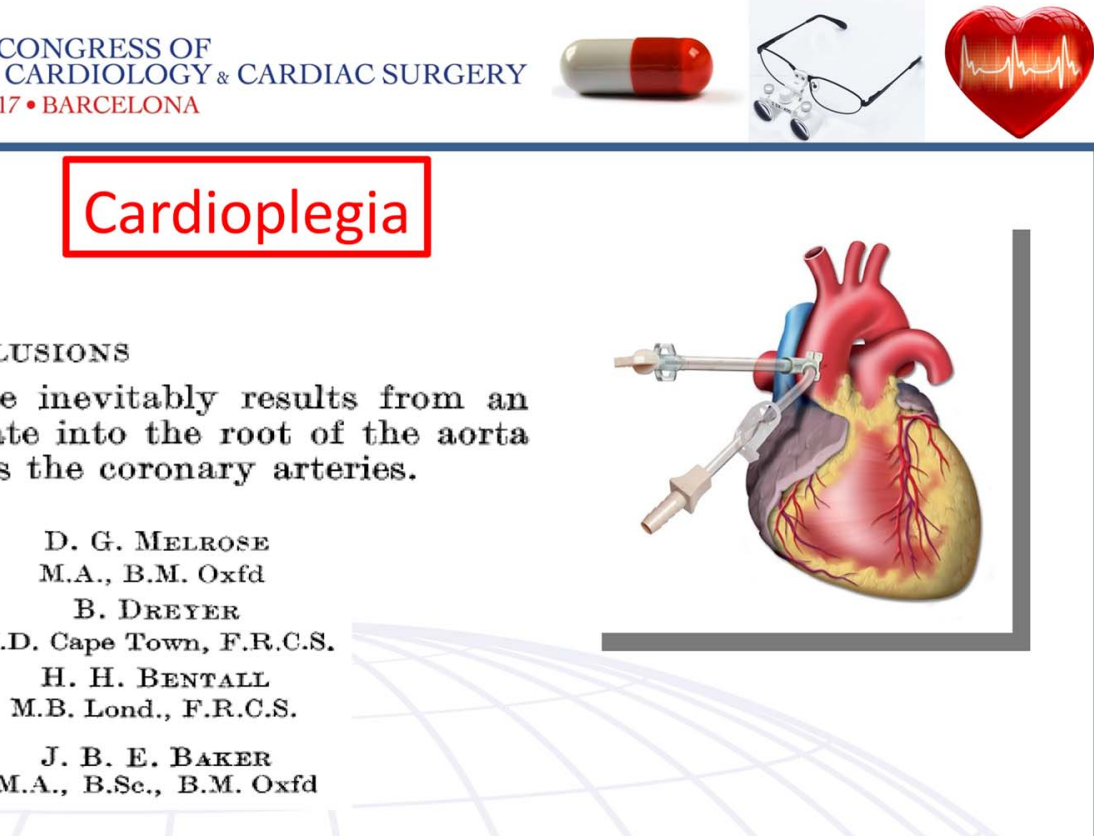

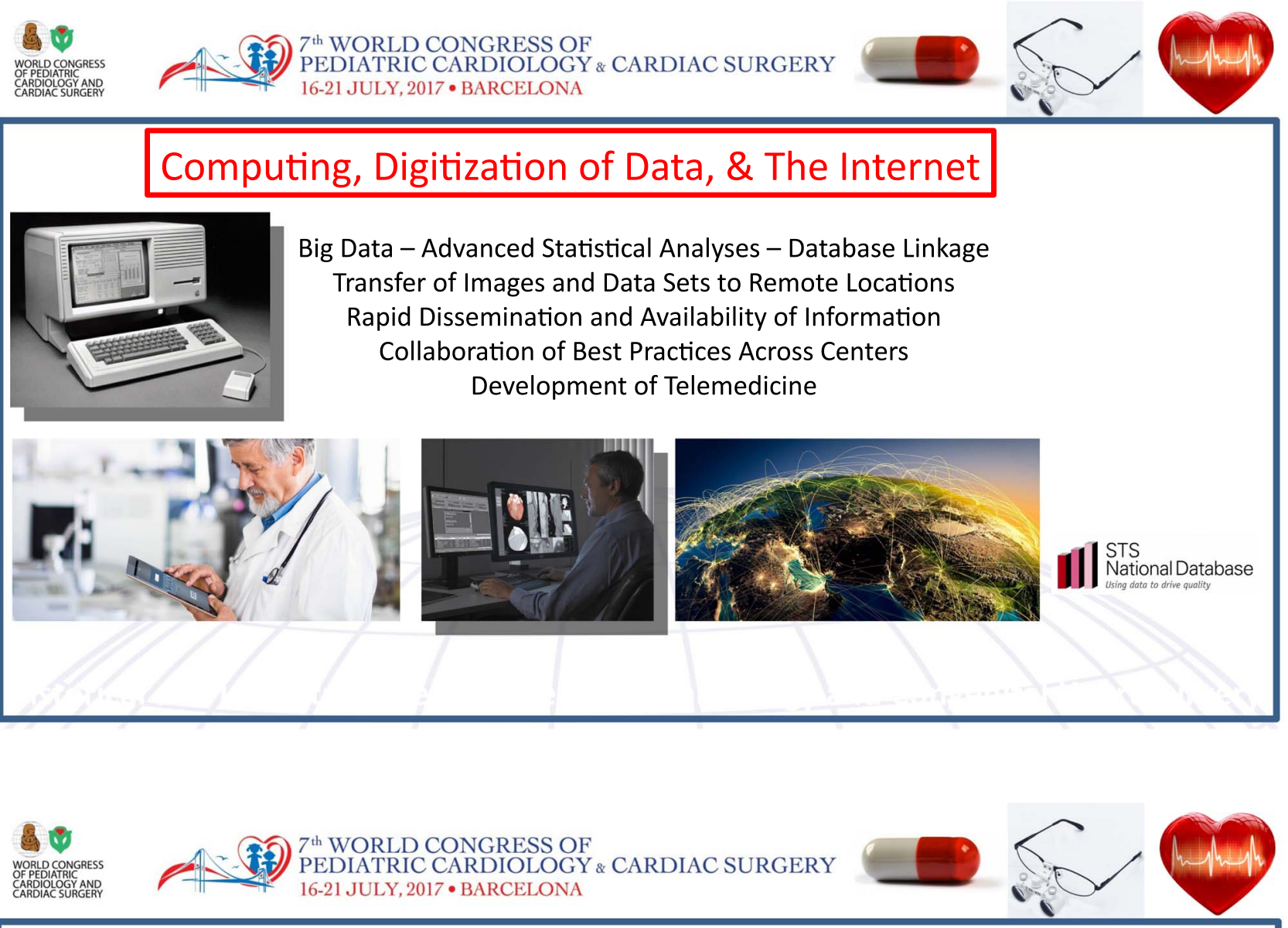

\section{Aprostadil (PGE1)}

Naturally occurring prostaglandin approved by the Food and Drug Administration (FDA) in 1981

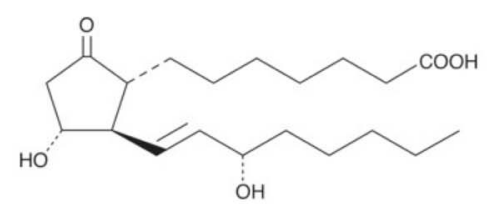

European Journal of Clinical Pharmacology

January 1980, Volume 18, 15sue 1, pp 75-81

Prostaglandins, ductus arteriosus, pulmonary circulation:

Current concepts and clinical potential

Dilatation of the Ductus Arteriosus by Prostaglandin $\mathrm{E}_{1}$ in Aortic Arch Abnormalities

Can J Physiol Pharmacol. 1973 Mar; 51(3):220-5.

The response of the ductus arteriosus to prostaglandins. Coceani F, Olley PM.

Michael A. Heymany, M.D, Winuay Berman, Jr, M.D. Abraham M. Rudolph, M.D., and Victor Whitman, M.D. 

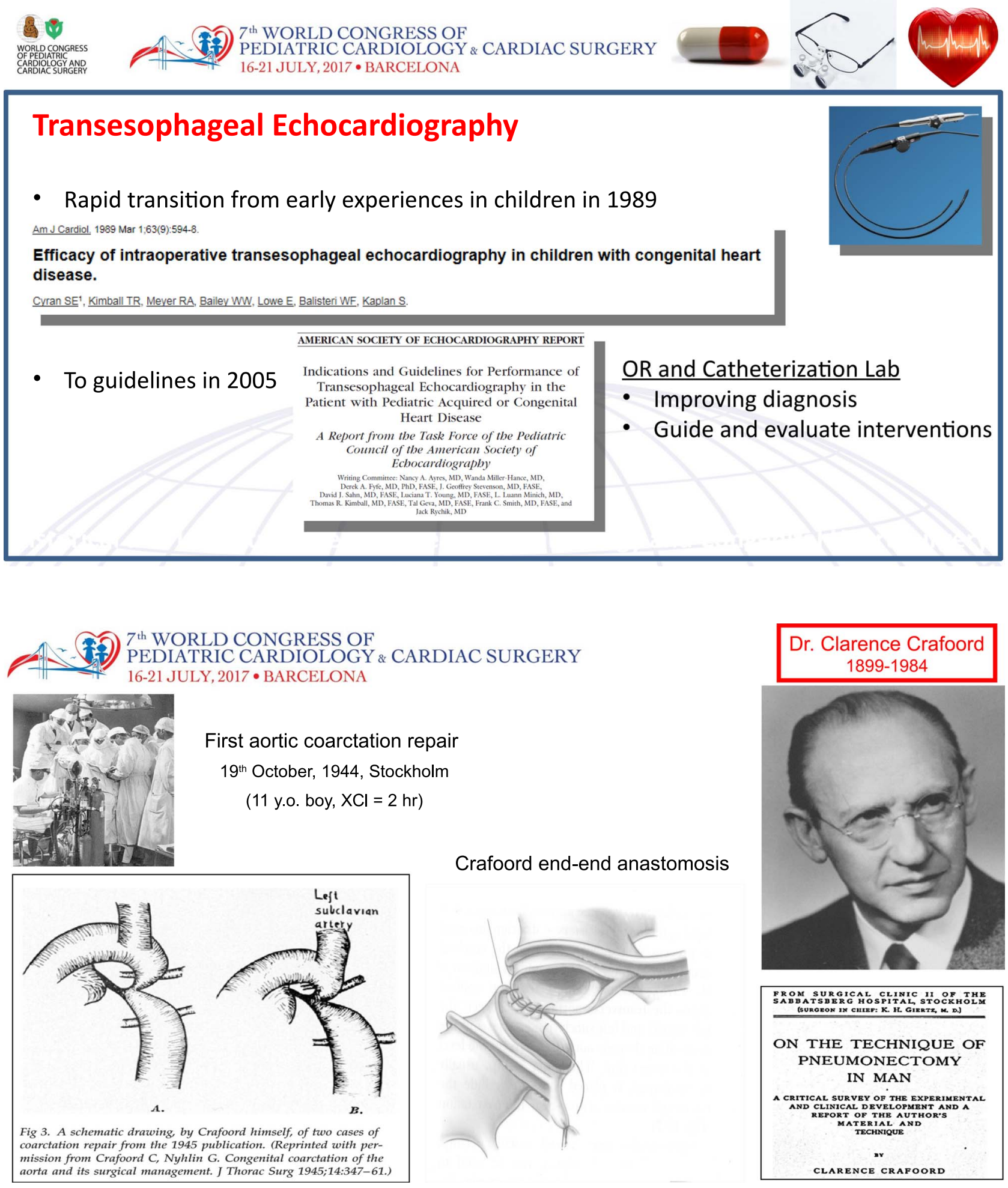

Crafoord end-end anastomosis
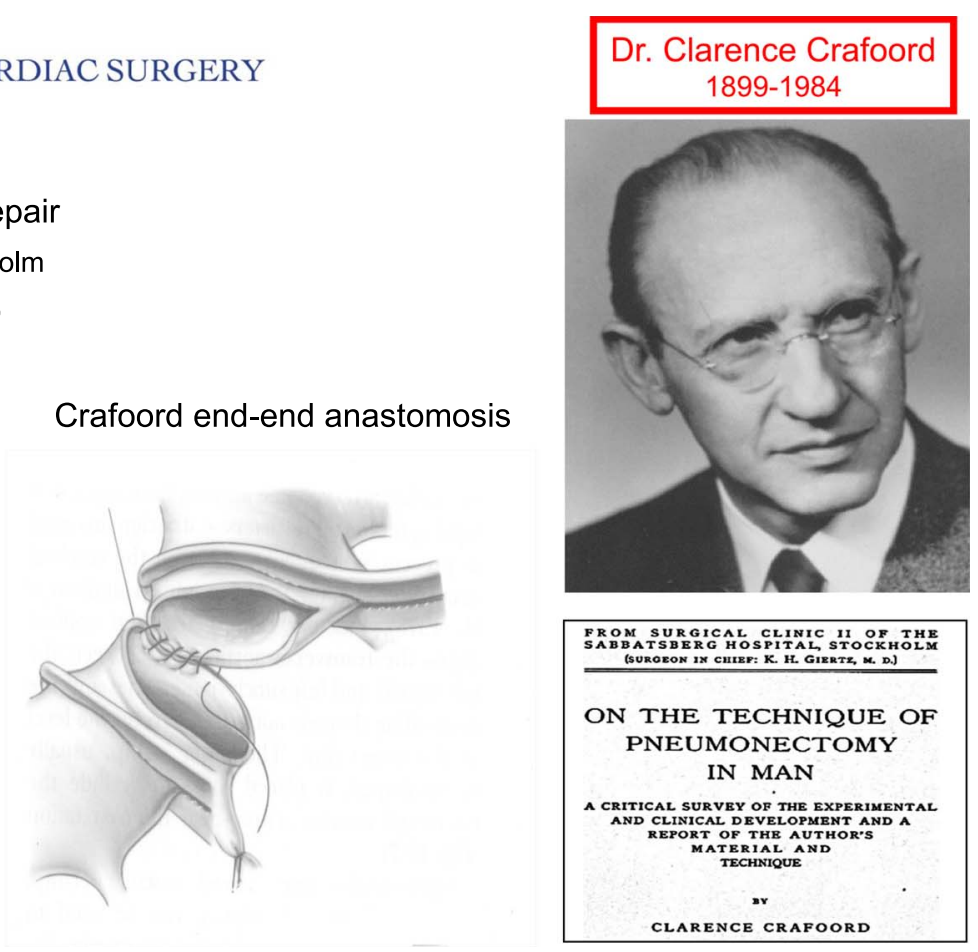


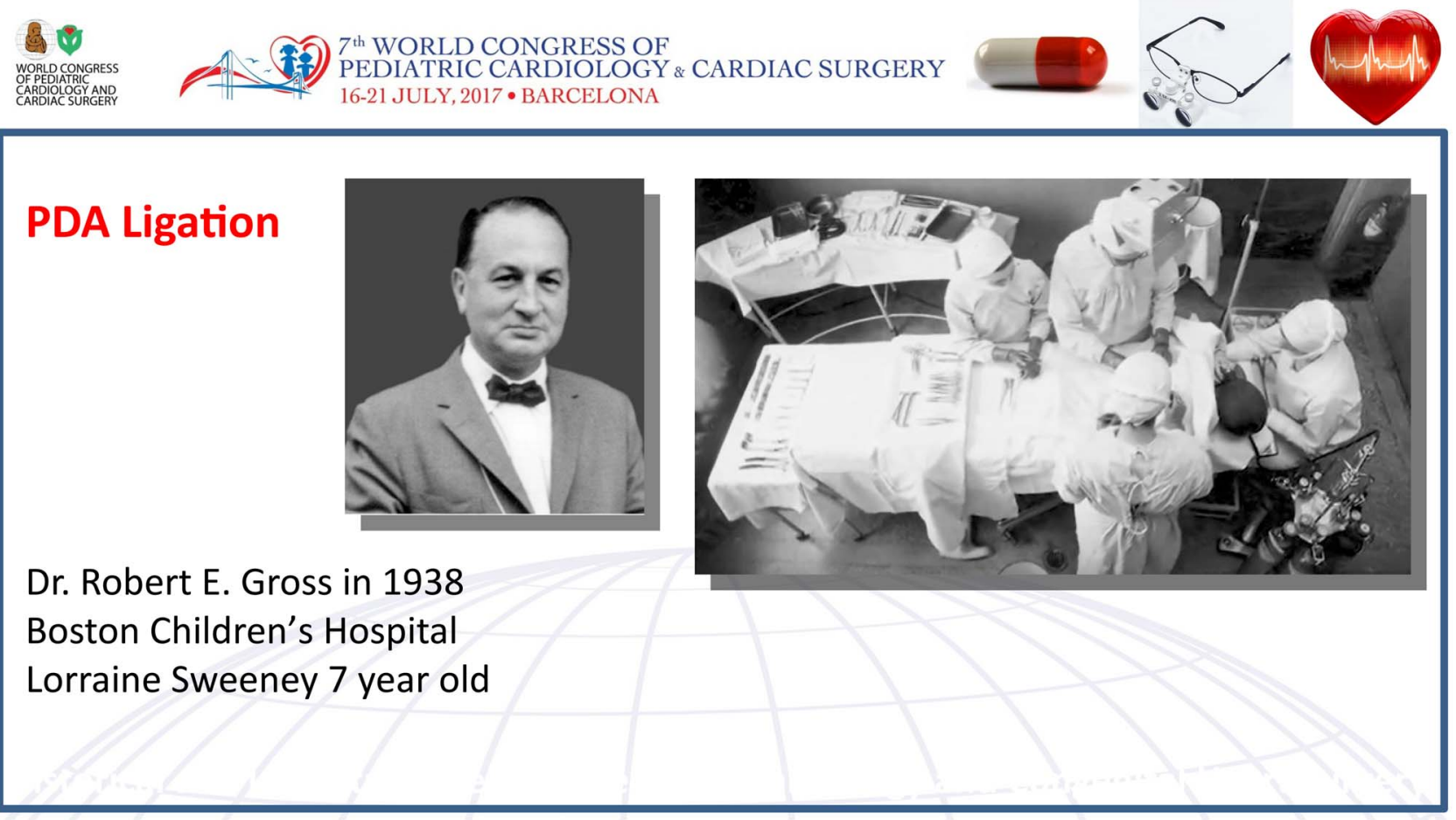

8 WORLD CONGRESS

$7^{\text {th }}$ WORLD CONGRESS OF PEDIATRIC CARDIOLOGY \& CARDIAC SURGERY 16-21 JULY, 2017 • BARCELONA
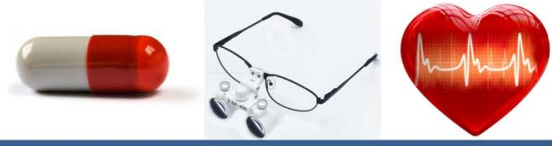

Clin Physiol Funct Imaaina. 2004 May;24(3):118-36.

The use of ultrasonic reflectoscope for the continuous recording of the movements of heart walls. 1954.

Edlerl, Hertz $\mathrm{CH}$.

Echocardiography

M-mode echocardiography

2 Dimensional echocardiography

Doppler echocardiography

Fetal Echocardiography

Color Flow Imaging

Transesophageal Imaging

3 Dimensional Echocardiography
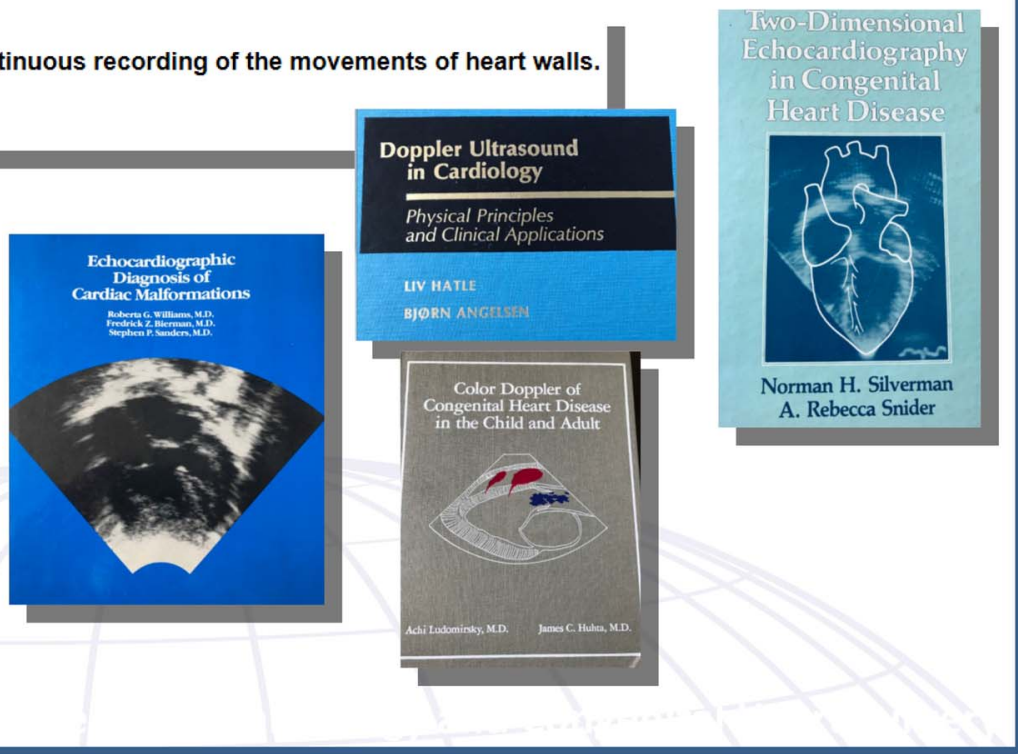

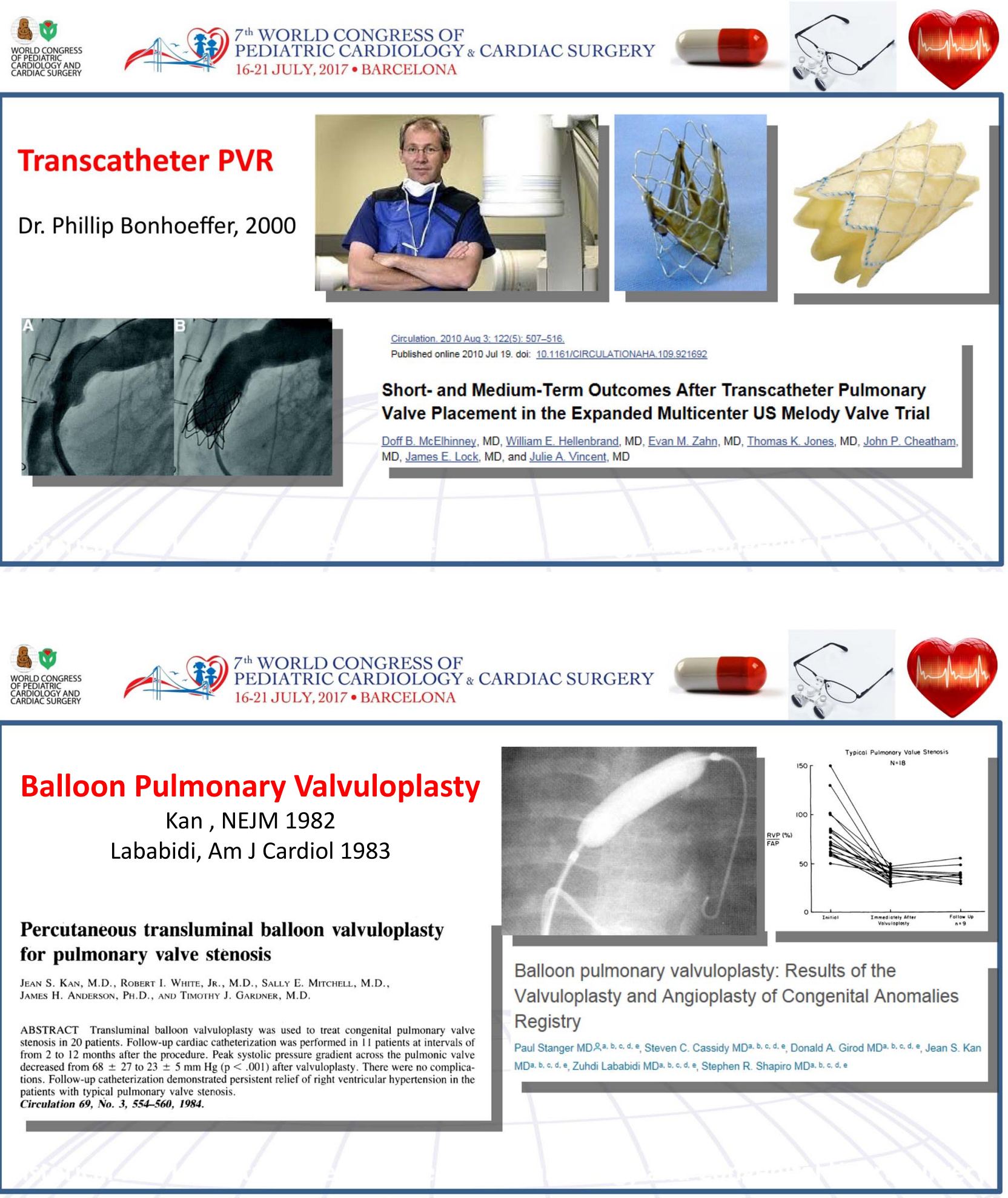


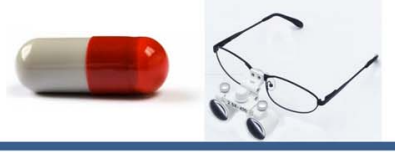

\section{Device Closure of ASD}

King \& Mills procedure in dogs, Surgery 1972

King-Mills Umbrella, in 17 year old girl, JAMA 1975

Rashkind Single Umbrella Device, Circulation 1983

Double Disc Approach: Lock, Mullins, Hellenbrand, 1989
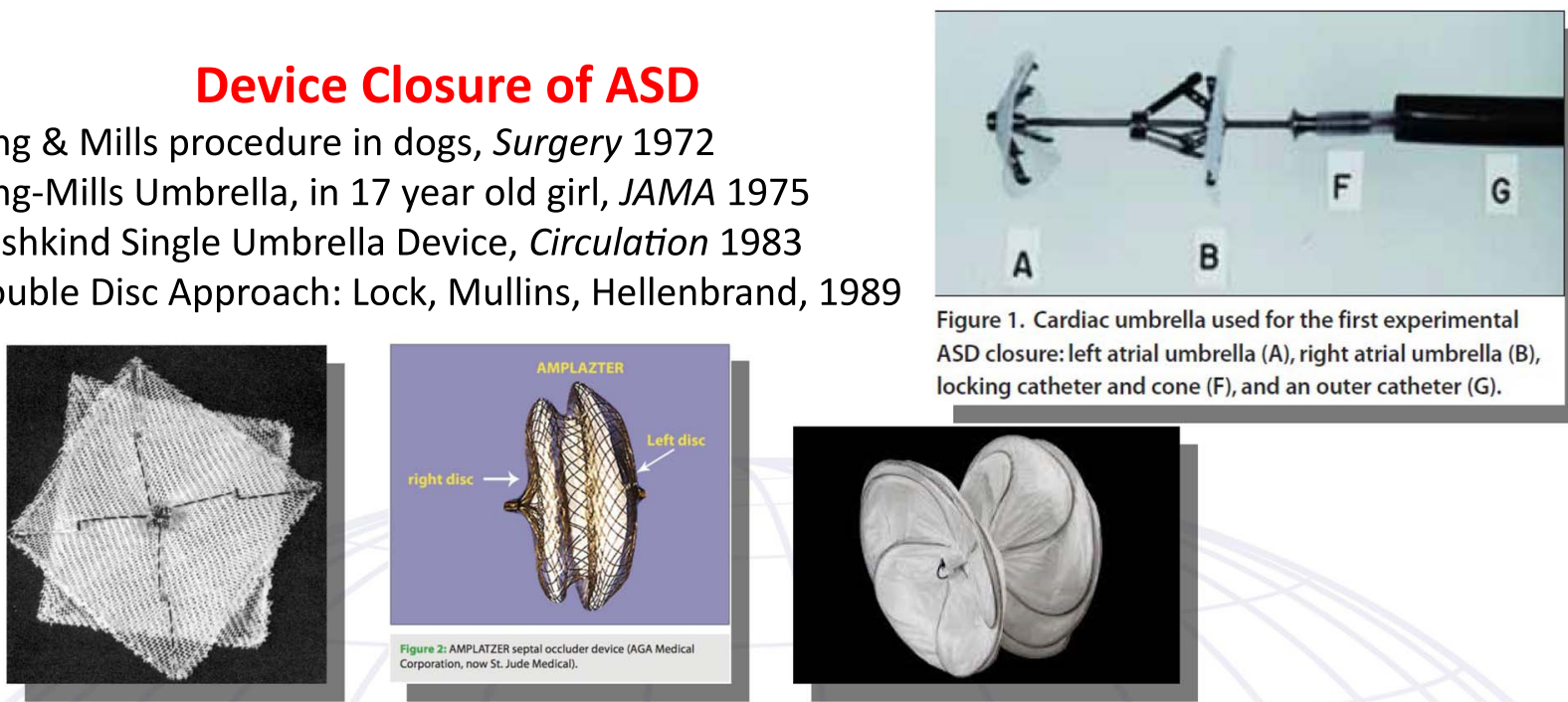

A

B

Figure 1. Cardiac umbrella used for the first experimental ASD closure: left atrial umbrella (A), right atrial umbrella (B), locking catheter and cone $(\mathrm{F})$, and an outer catheter $(\mathrm{G})$.

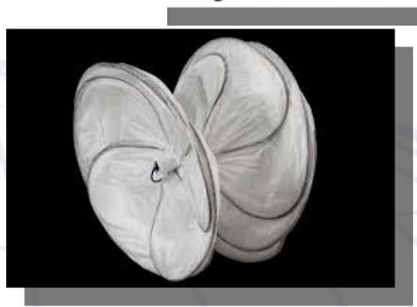

\section{6}

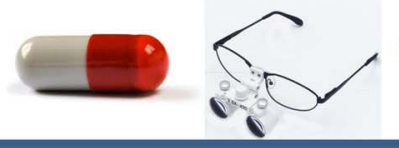

Device Closure of PDA

First report by Portsman 1967

Rashkind Double Disc 1979

Hellenbrand 2004 (Multi-center Trial)
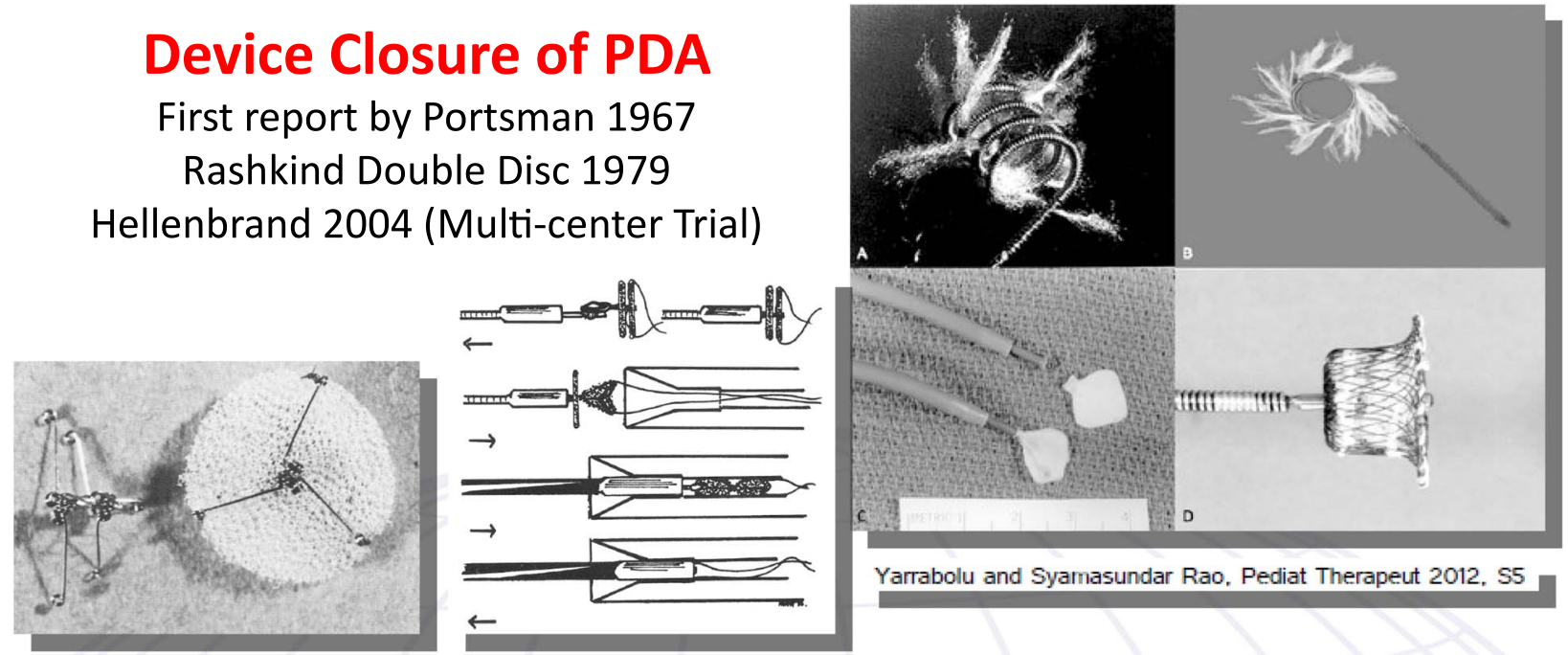

Yarrabolu and Syamasundar Rao, Pediat Therapeut 2012, S5 

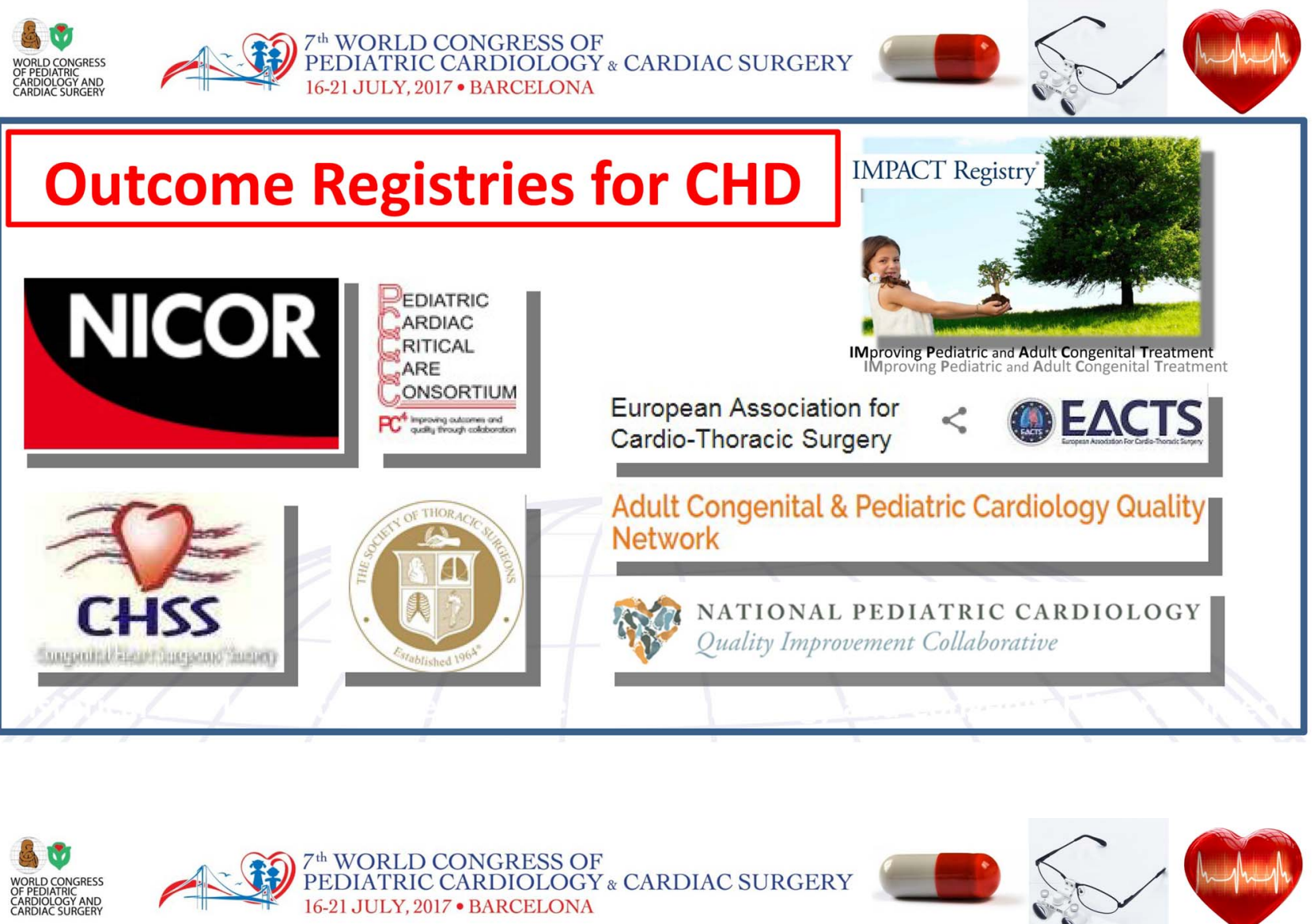

$7^{\text {th }}$ WORLD CONGRESS OF

PEDIATRIC CARDIOLOGY \& CARDIAC SURGERY 16-21 JULY, $2017 \bullet$ BARCELONA
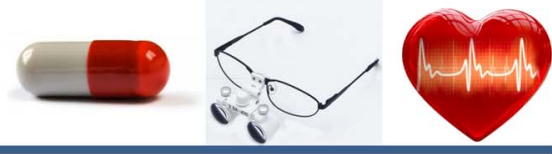

\section{Fetal Echocardiography}

First articles......1969

Ann Obstet Ginecol Med Perinat. 1969 Jul;91(7):491-6.

- The fetal echo-cardiogram

- Kratochwil A, Sassi D.

Invest Radiol. 1972 May-Jun;7(3):152-8.

- Echocardiography of the fetal and newborn heart.

- Winsberg F.

J Clin Ultrasound. 1975 Jun;3(2):95-105.

- Ultrasonic identification and examination of fetal heart structures.

- Egeblad H, Bang J, Northeved A.

Major Early Investigators

- Charles Kleinman

- Liv Hatle

- David Sahn

- Norman Silverman
Diagnosis and Treatment of Fetal Cardiac Disease: A Scientific Statement From the American Heart Association

Mary T. Donofrio, Anita J. Moon-Grady, Lisa K. Hornberger, Joshua A. Copel, Mark S Sklansky, Alfred Abuhamad, Bettina F. Cuneo, James C. Huhta, Richard A. Jonas, Anita Krishnan, Stephanie Lacey, Wesley Lee, Erik C. Michelfelder, Sr, Gwen R. Rempel, Norman H.

Silverman, Thomas L. Spray, Janette F. Strasburger, Wayne Tworetzky and Jack Rychik

on behalf of the American Heart Association Adults With Congenital Heart Disease Joint

Committee of the Council on Cardiovascular Disease in the Young and Council on Clinical Cardiology, Council on Cardiovascular Surgery and Anesthesia, and Council on Cardiovascular and Stroke Nursing
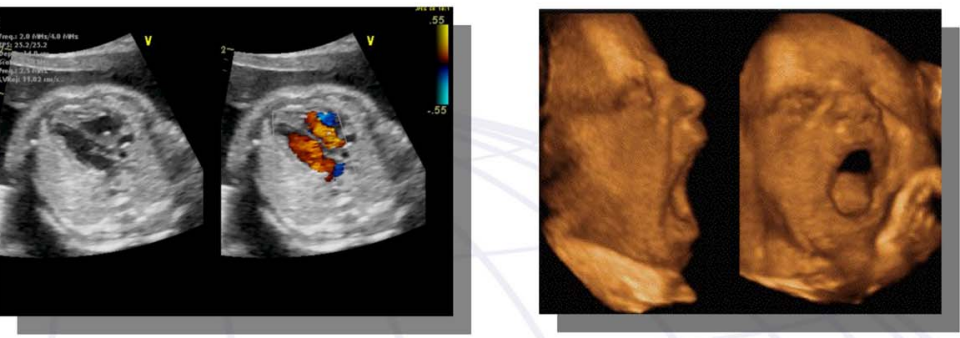


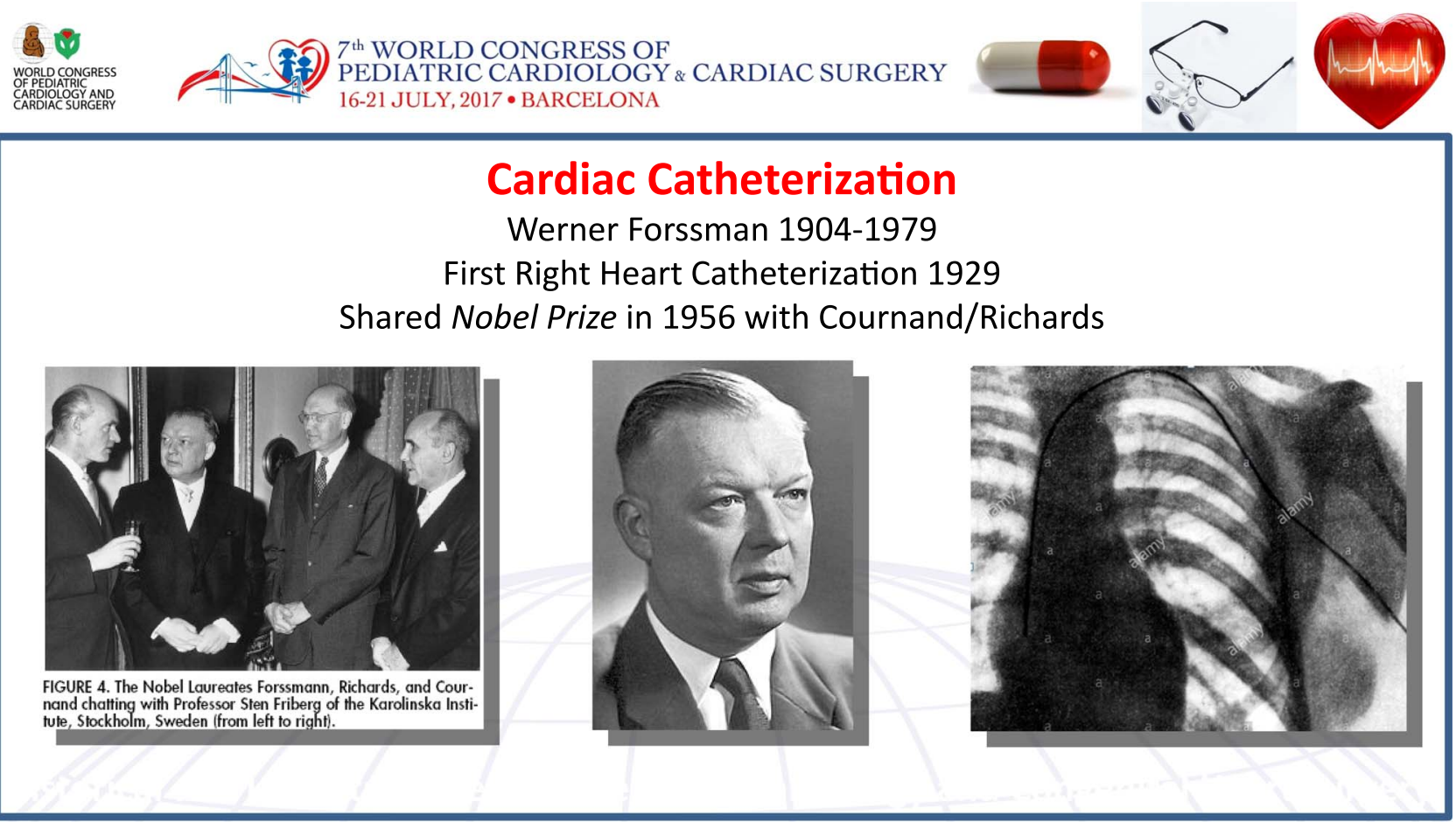

86 WORLD CONGRESS CARDOLOGY AND
CARDIAC SURGERY

(?) $7^{\text {th }}$ WORLD CONGRESS OF PEDIATRIC CARDIOLOGY \& CARDIAC SURGERY 16-21 JULY, 2017 • BARCELONA

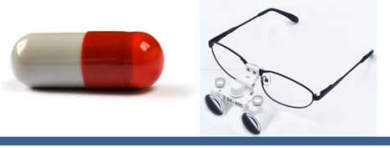

\section{Electrocardiography}

Willem Einthoven (1860-1927)

MD from University of Utrecht

String galvanometer to record ECG

ECG without direct leads on heart 1903

Described P,Q,R,S,T waves

Nobel Prize in 1924
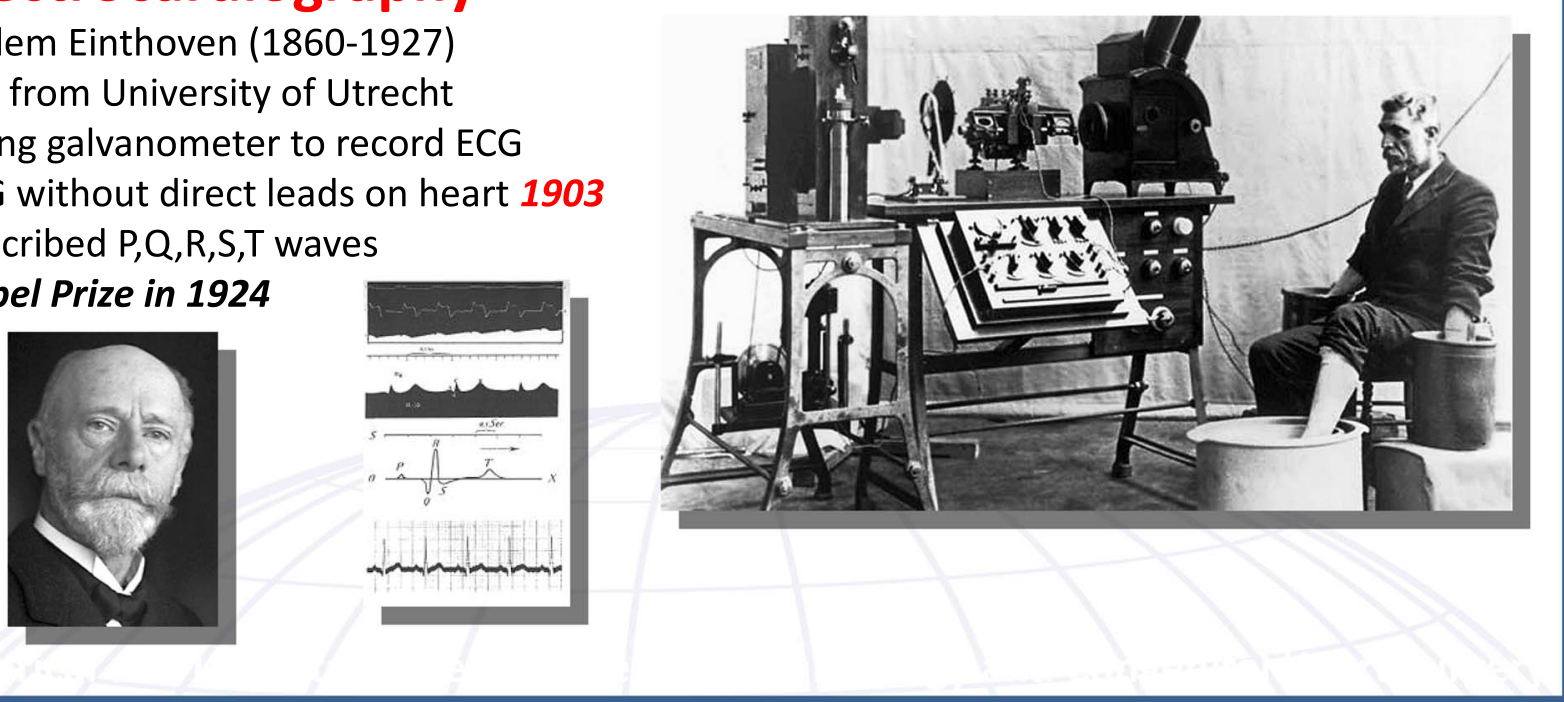

(continued) 


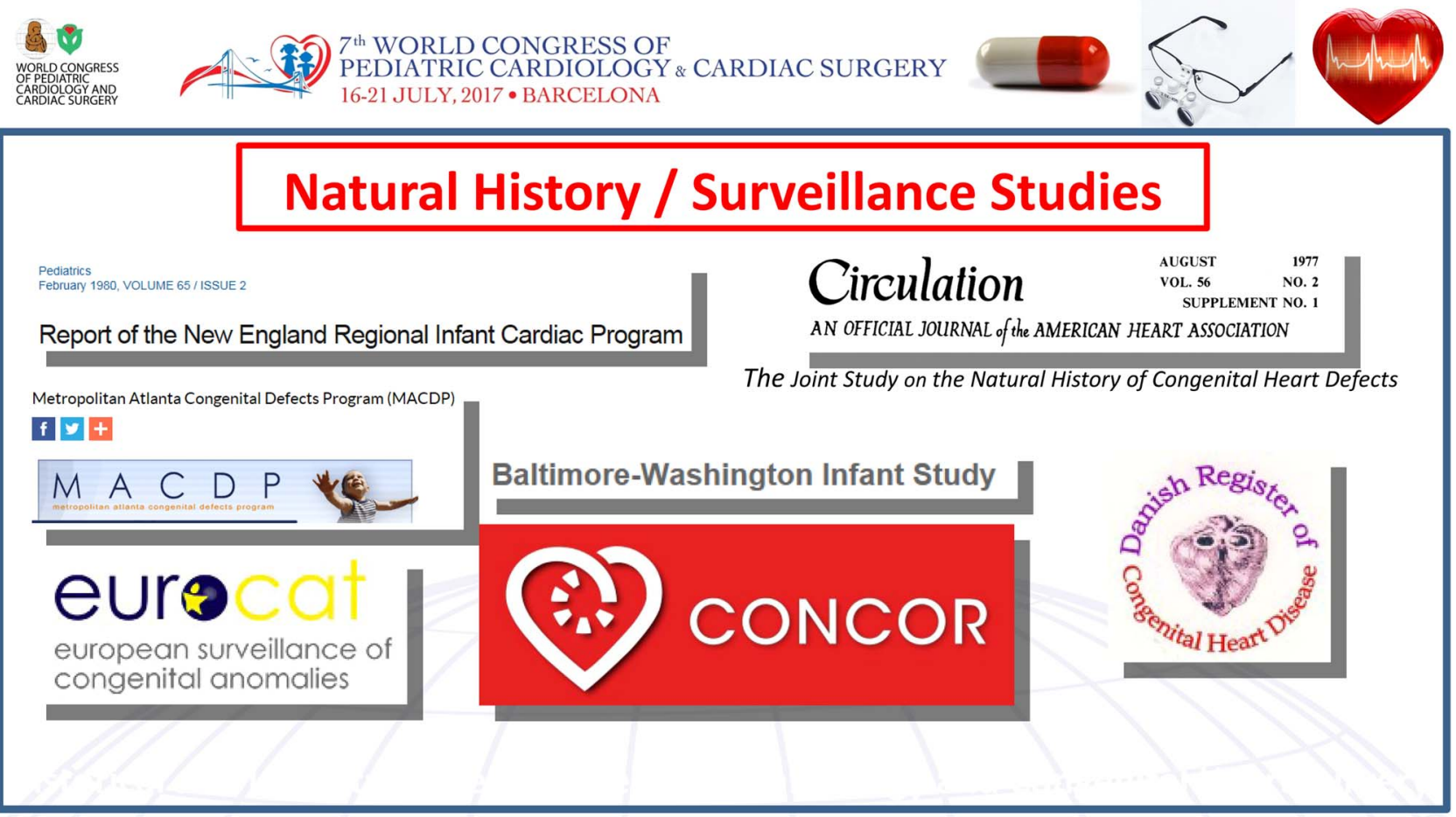

S6) WORL CONGGESS Con
CARDDOOOCY AND
CARDIACSURGERY
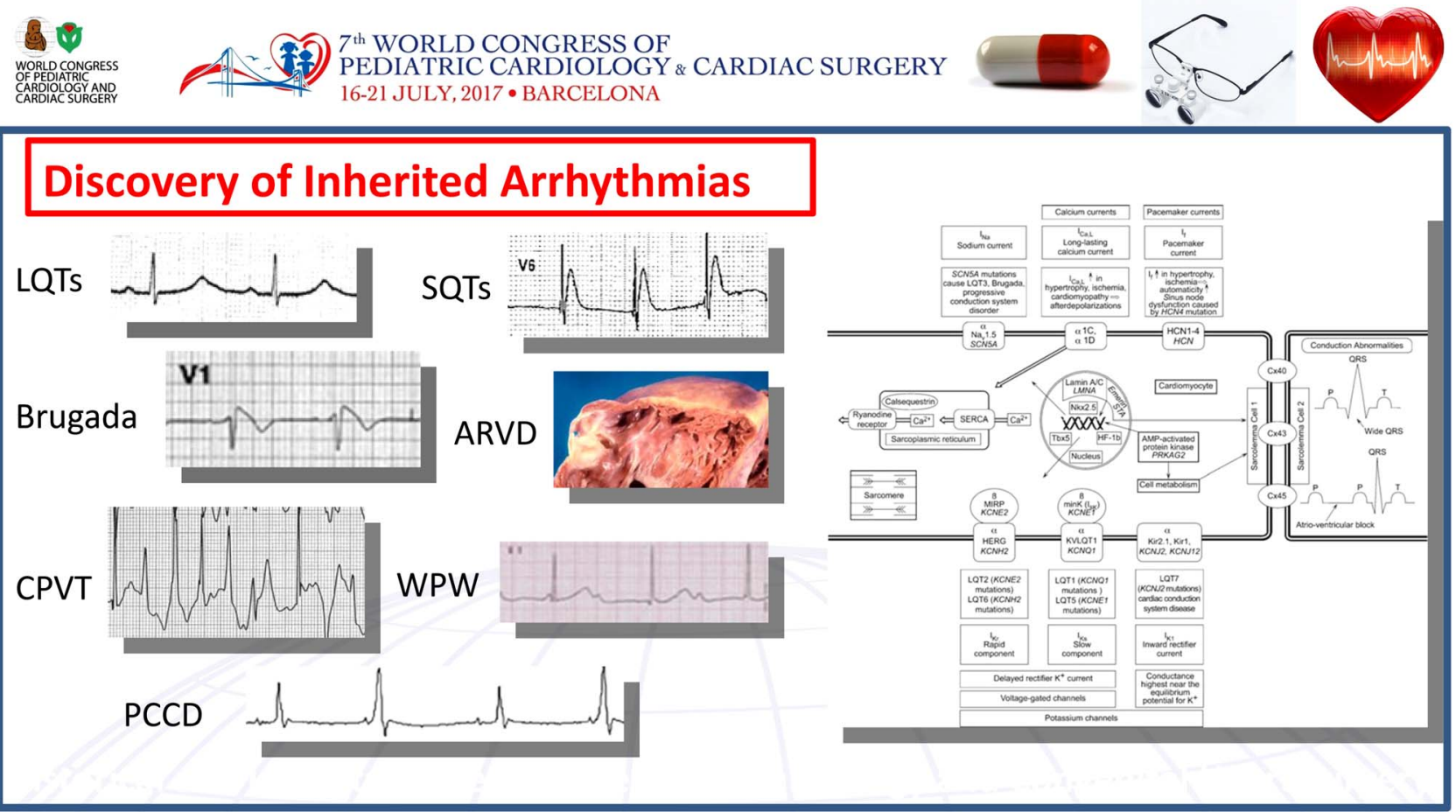

(continued) 


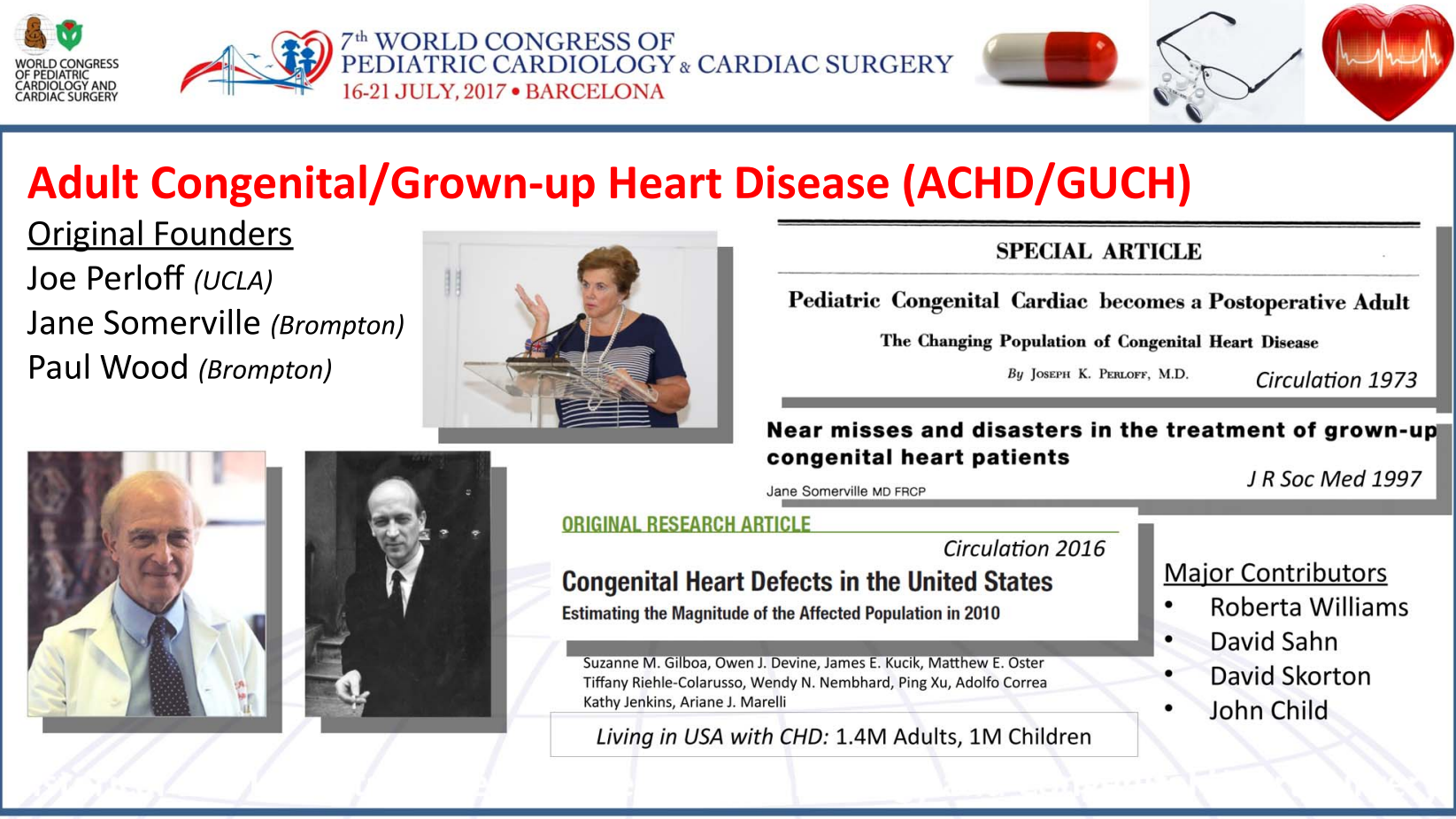
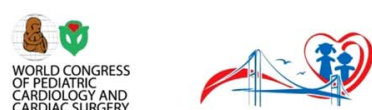

$7^{\text {th }}$ WORLD CONGRESS OF

PEDIATRIC CARDIOLOGY \& CARDIAC SURGERY 16-21 JULY, $2017 \bullet$ BARCELONA
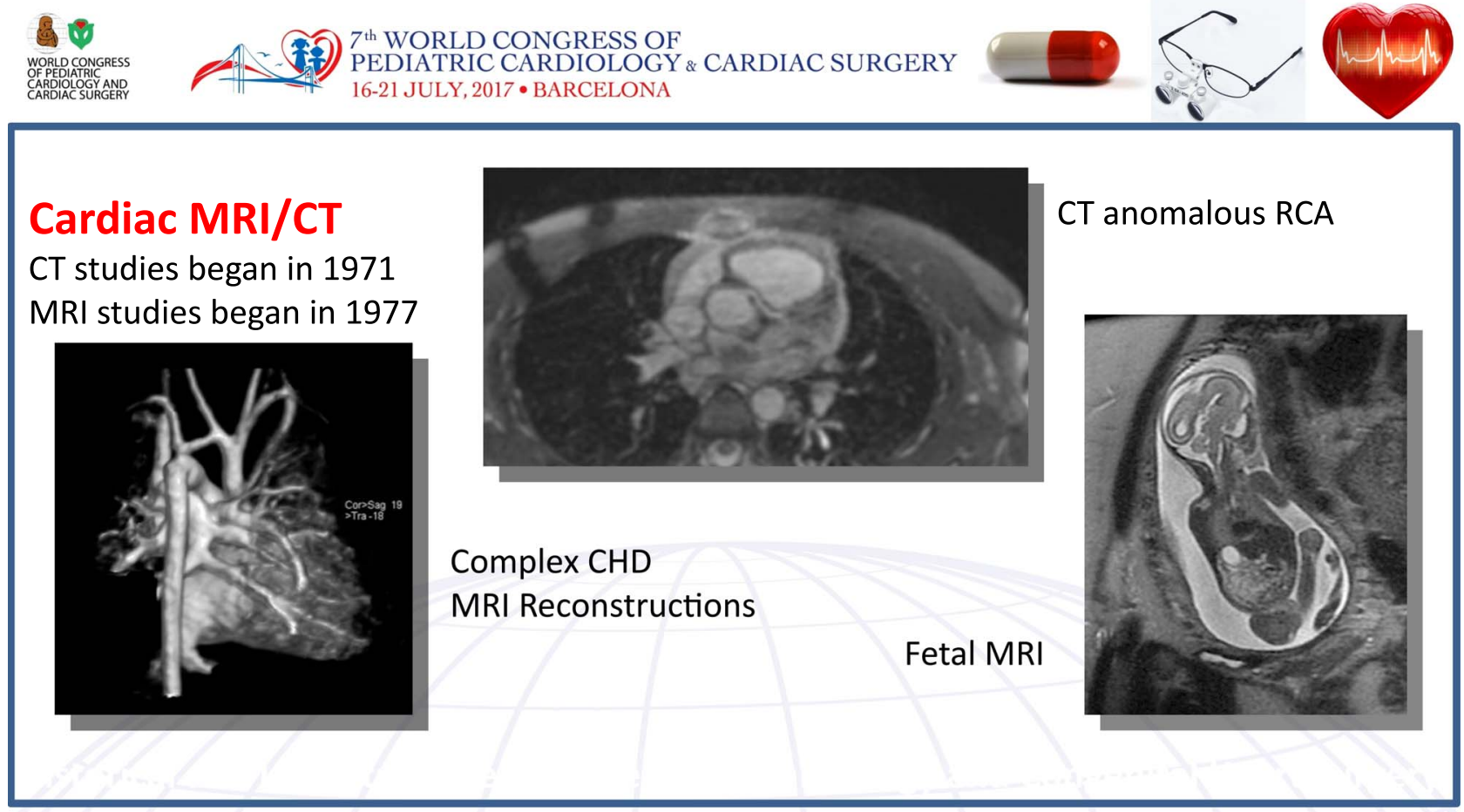

(continued) 


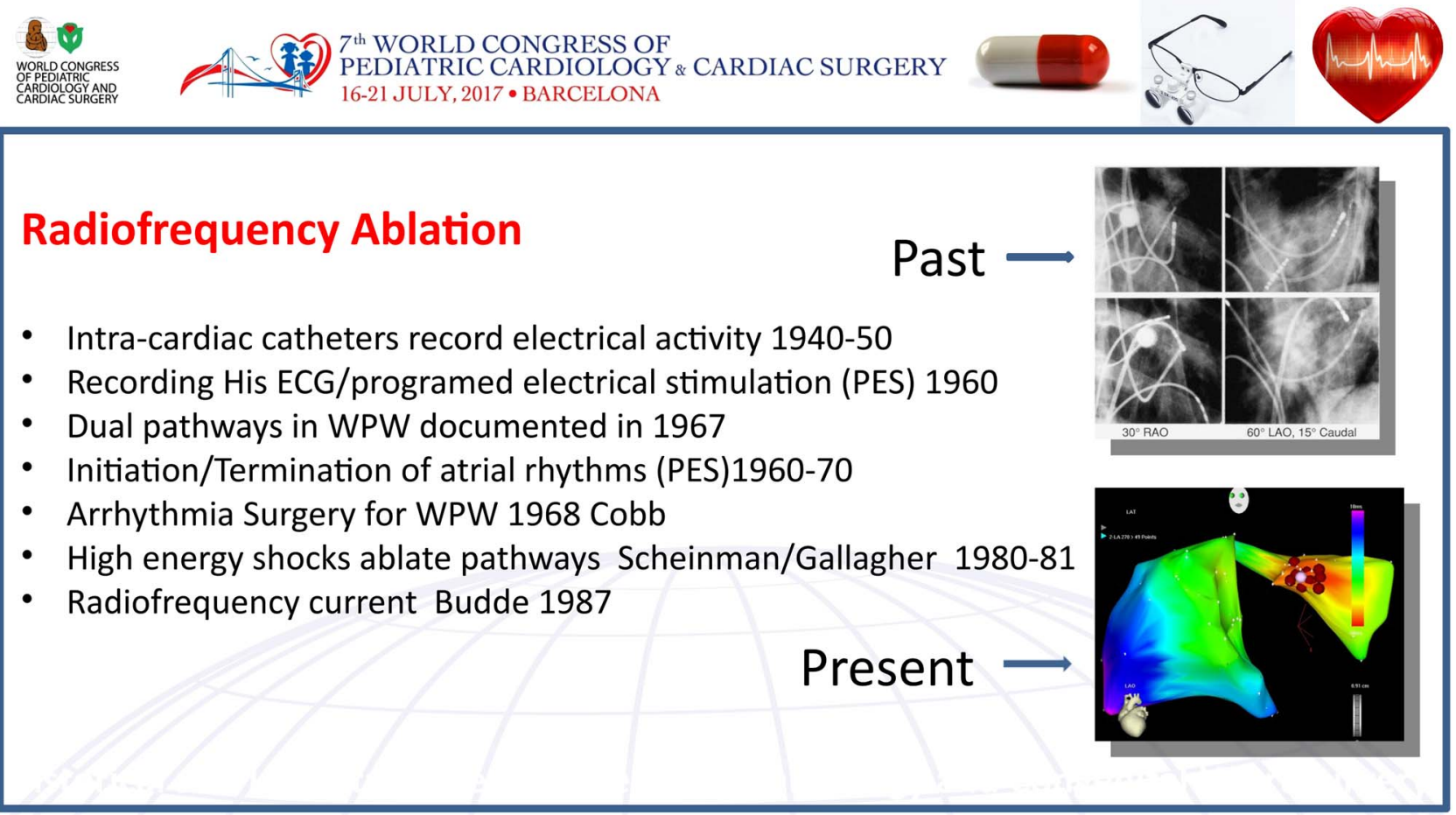

(2) $7^{\text {th }}$ WORLD CONGRESS OF PEDIATRIC CARDIOLOGY \& CARDIAC SURGERY 16-21 JULY, $2017 \bullet$ BARCELONA Rastelli, G.C. A new approach to "anatomic" repair of transposition. Mayo Clin Proc 1969;44:1-12.
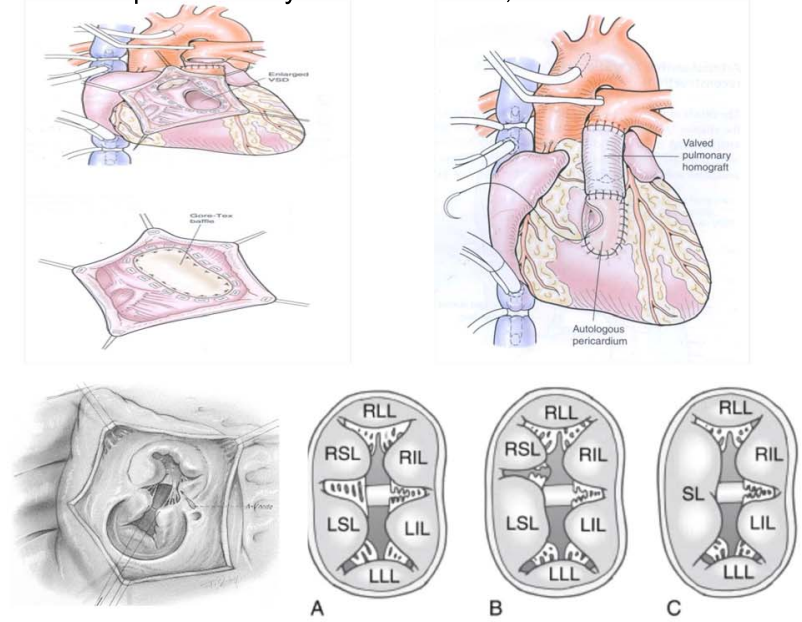

\section{Giancarlo Rastelli}

1933-1970 (Parma, Italy and Rochester, USA)

Rastelli GC, Kirklin JW, Titus JL: Anatomic observations on complete form of persistent common AV with special reference to AV valves. Mayo Clin Proc 1966;41:296.
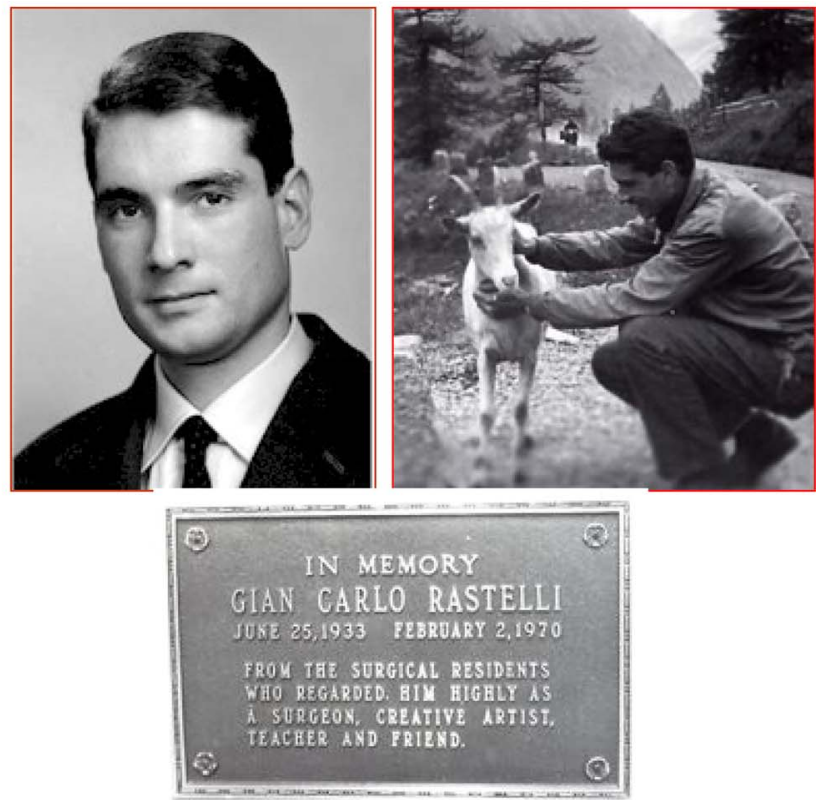
$7^{\text {th }}$ WORLD CONGRESS OF

PEDIATRIC CARDIOLOGY \& CARDIAC SURGERY

16-21 JULY, $2017 \bullet$ BARCELONA

\section{Donald N. Ross}

\section{Ross Operation 1967}

GUY'S HOSPITAL AND NATIONAL HEART HOSPITAL, LONDON

\section{REPLACEMENT OF AORTIC AND MITRAL VALVES WITH A PULMONARY AUTOGRAFT}

The finding of late degenerative changes in a proportion of aortic homografts prompted the use of the patient's own pulmonary valve as a replacement. As a living autograft, the transplanted pulmonary valve has the prospect of long-term or permanent survival, whilst retaining the advantages of an aortic homograft. Similarly it can be used to replace the mitral valve. The excised pulmonary valve is replaced with a homograft.
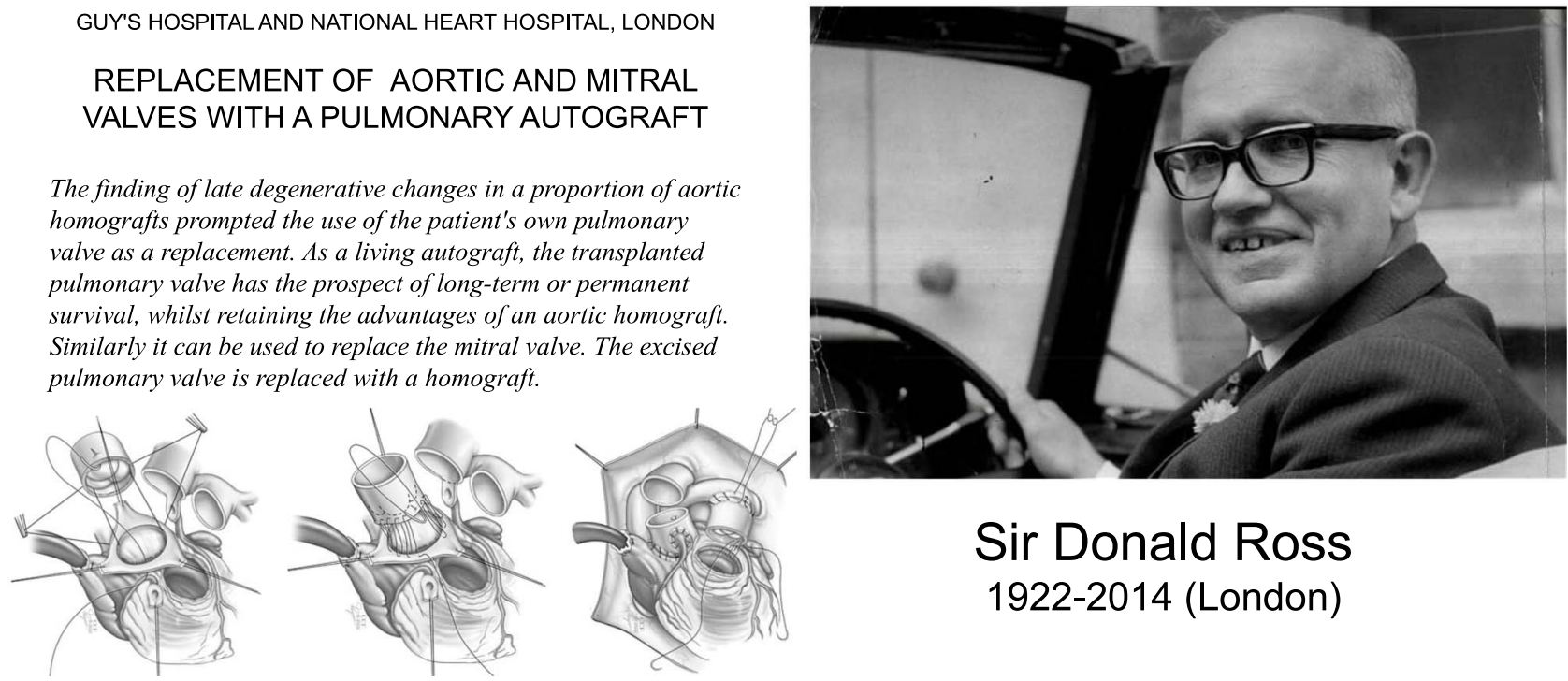

\section{Sir Donald Ross} 1922-2014 (London)

\section{7. $7^{\text {th }}$ WORLD CONGRESS OF} PEDIATRIC CARDIOLOGY \& CARDIAC SURGERY 16-21 JULY, $2017 \bullet$ BARCELONA

"There are limits to our knowledge, but no limits to our ignorance."

Dr. Marc R. de Leval London, UK

VSD closure technique in ccTGA

Fontan technical modifications (TCPC)

Computational fluid dynamics of Fontan circuit

Role of the lymphatic system in Fontan physiology

Analysis of human error in cardiac surgery

Extraordinary mentor and humanist
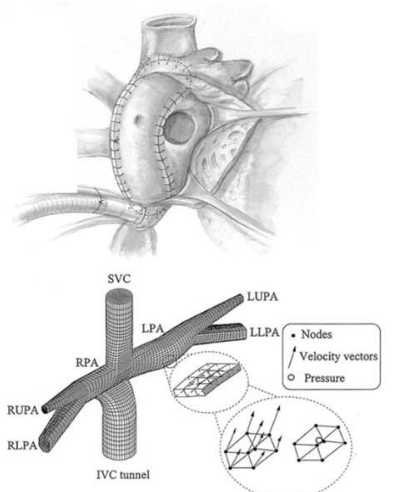

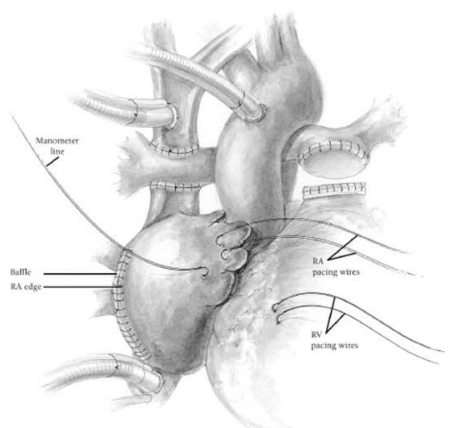

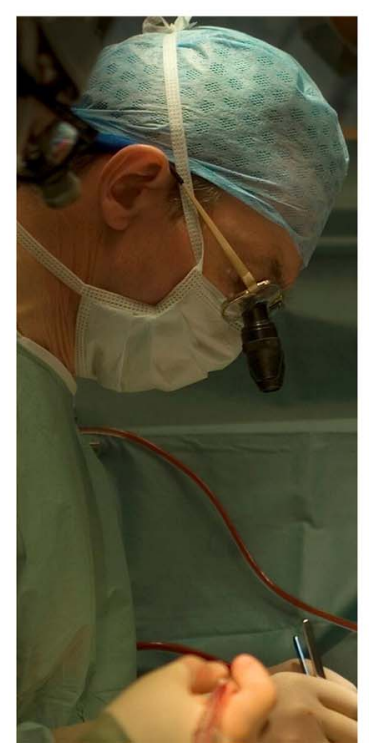

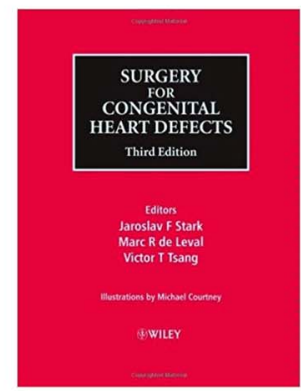

Marc R. de Leval Fellowship 
192 $7^{\text {th }}$ WORLD CONGRESS OF

PEDIATRIC CARDIOLOGY \& CARDIAC SURGERY 16-21 JULY, 2017 •BARCELONA
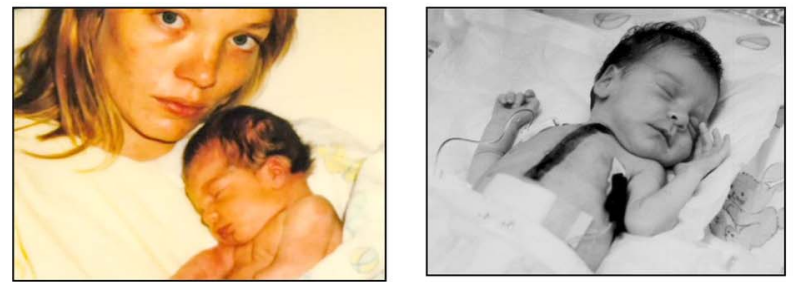

Teresa and Stephanie Fae Beauclair
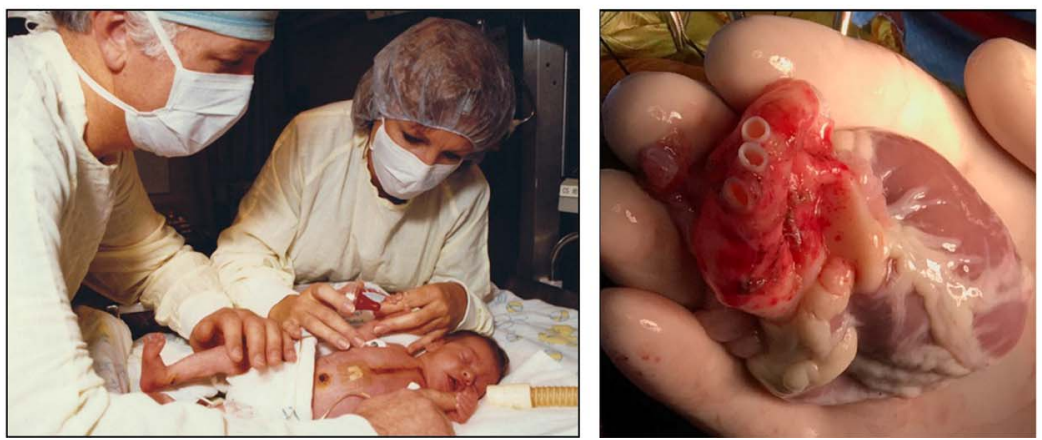

\section{Dr. Leonard Bailey} Loma Linda, USA

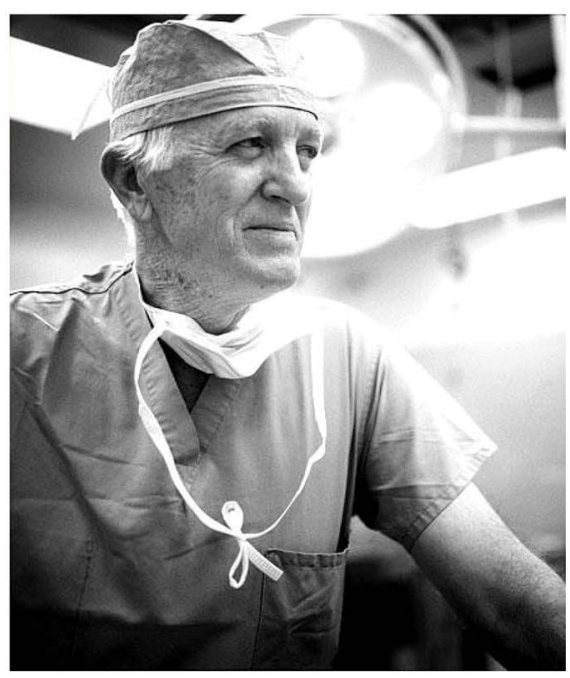

Neonatal cardiac xenotransplant $26^{\text {th }}$ October 1984

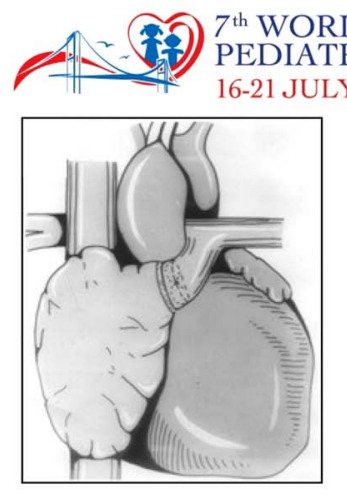

Kreutzer G, Galíndez E, Bono $\mathrm{H}$, De Palma C, Laura JP. An operation for the correction of tricuspid atresia. JTCVS 1973;66:613-21.

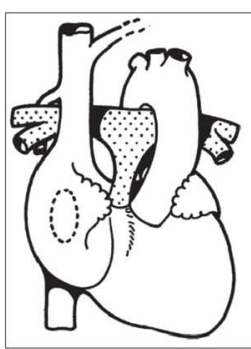

Fontan F, Baudet P. Surgical repair of tricuspid atresia. Thorax 1971;26: 240-248.

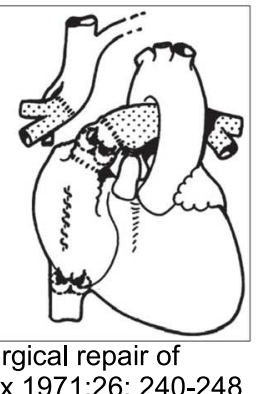

Dr. Guillermo Kreutzer Buenos Aires
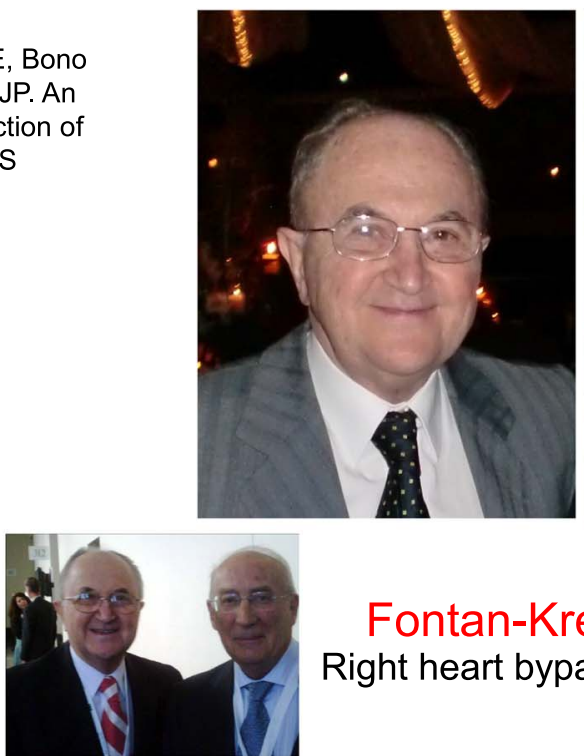

Dr. Francis Fontan Bordeaux

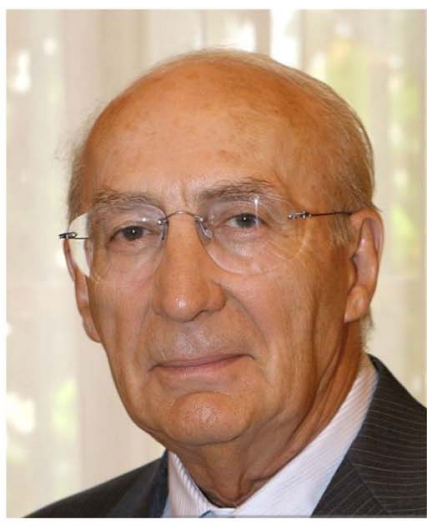

Fontan-Kreutzer operation Right heart bypass for tricuspid atresia 

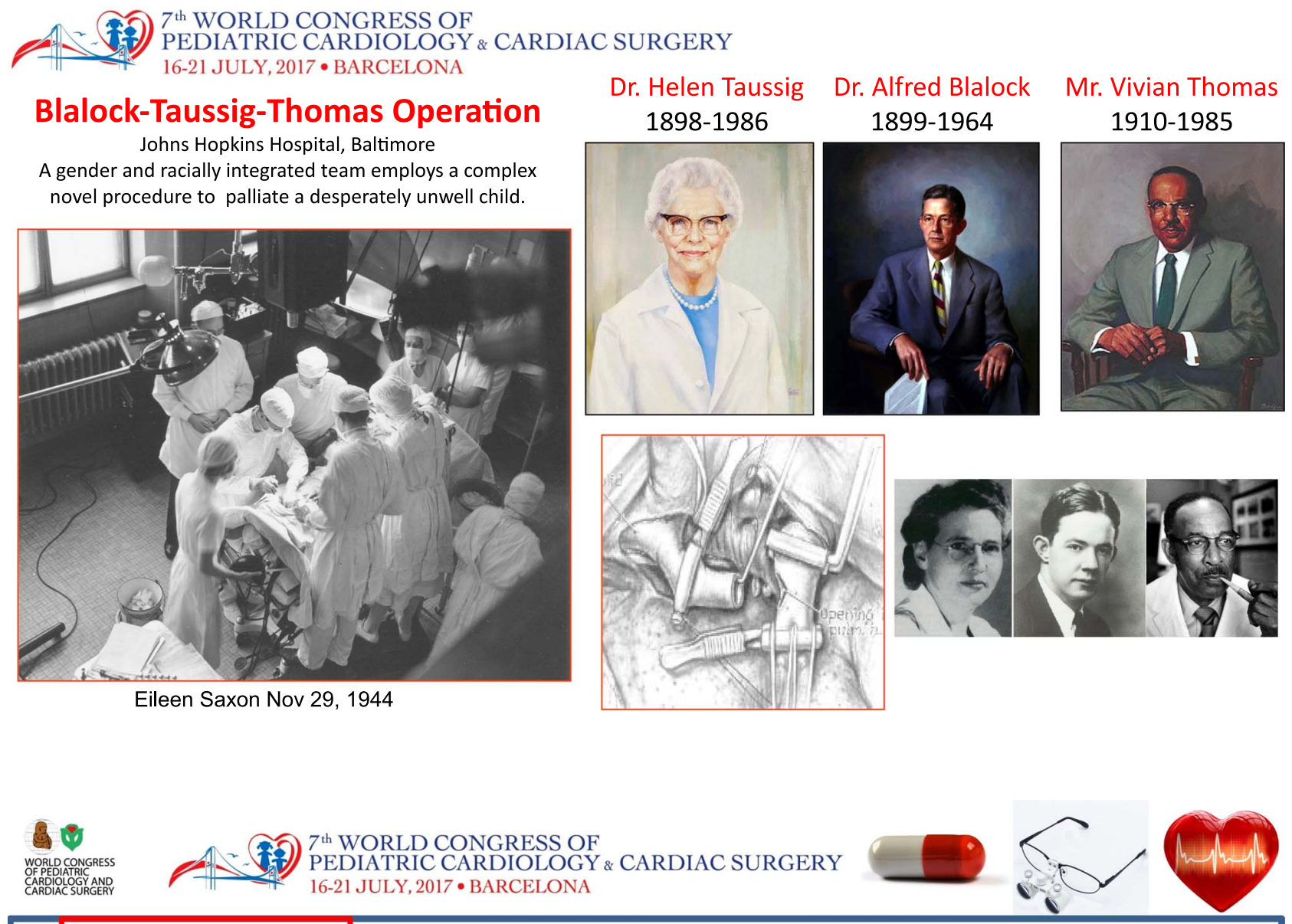

\section{Kurt Amplatz 1924-}

Born in Austria; emigrated to US 1953 40 year Career at University of Minnesota 1983 Malcolm P. Hansen Professor of Radiology Co-founded AGA Medical Corporation

Frequently described as "a simple country doctor" Designed and created multiple devices widely used in interventional procedures
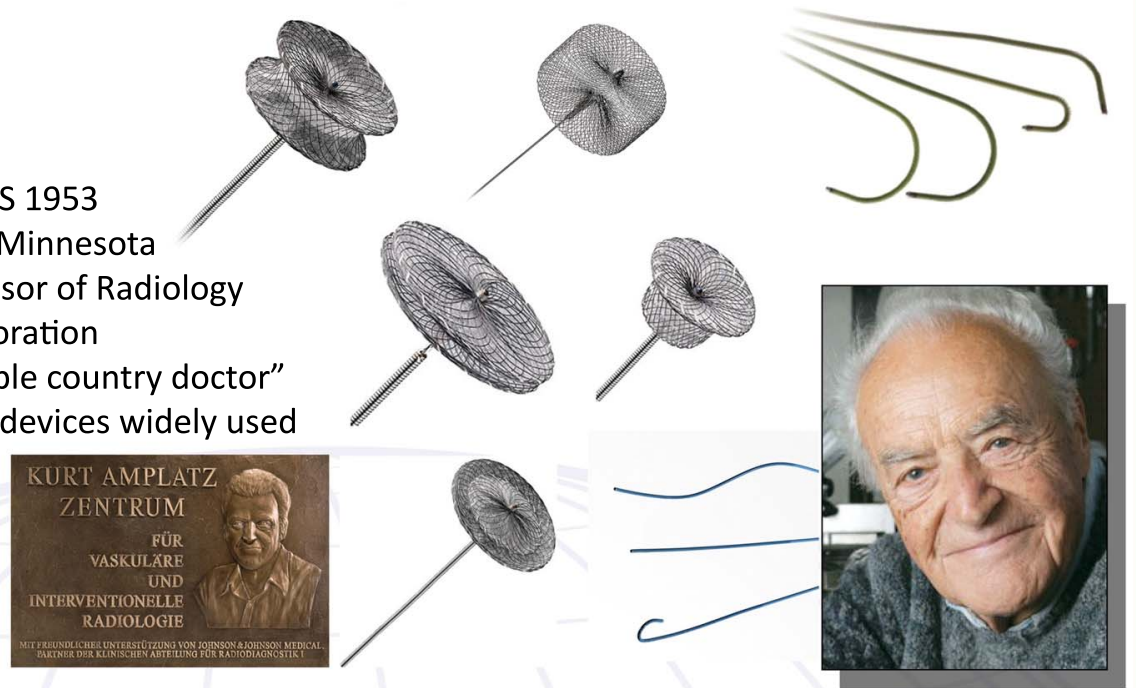
(2) $7^{\text {th }}$ WORLD CONGRESS OF

PEDIATRIC CARDIOLOGY \& CARDIAC SURGERY

16-21 JULY, 2017 • BARCELONA

\section{Cross circulation 1954-1955}

University of Minnesota
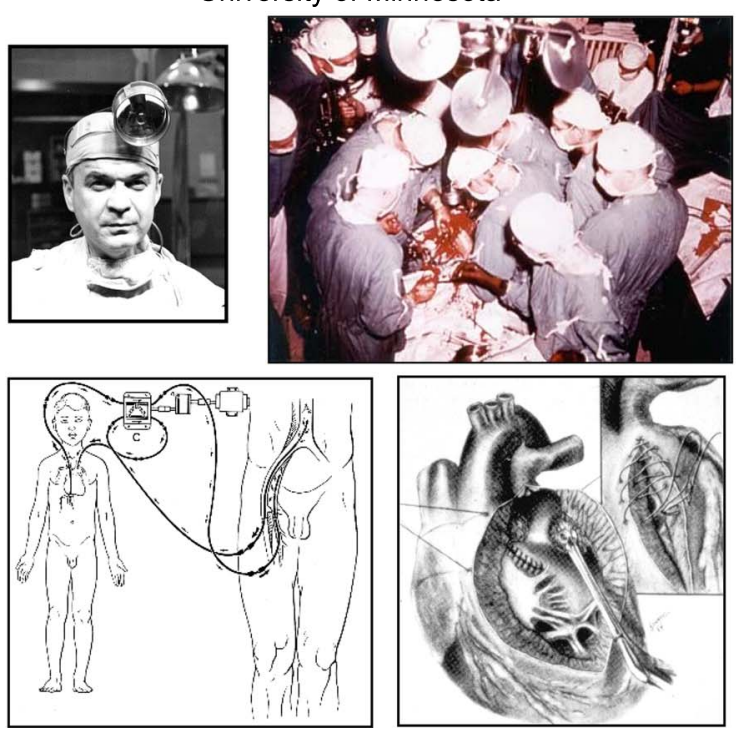

Dr. C. Walton Lillehei (1918-1999)

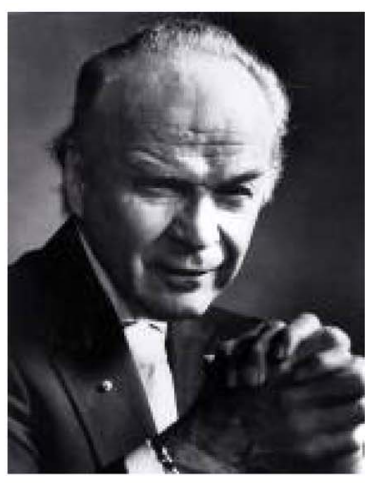

45 patients with major cardiac malformations underwent open repair utilizing cross-circulation (VSD, TOF, AVSD)

Twenty-seven patients ( $>50 \%$ infants), had VSD closure

Eight hospital deaths, 2 late deaths @ 30 year f/u, with seventeen 30 year survivors in NYHA Class I

At least 820 cardiothoracic surgeons in 36 countries can trace their surgical lineage to Lillehei

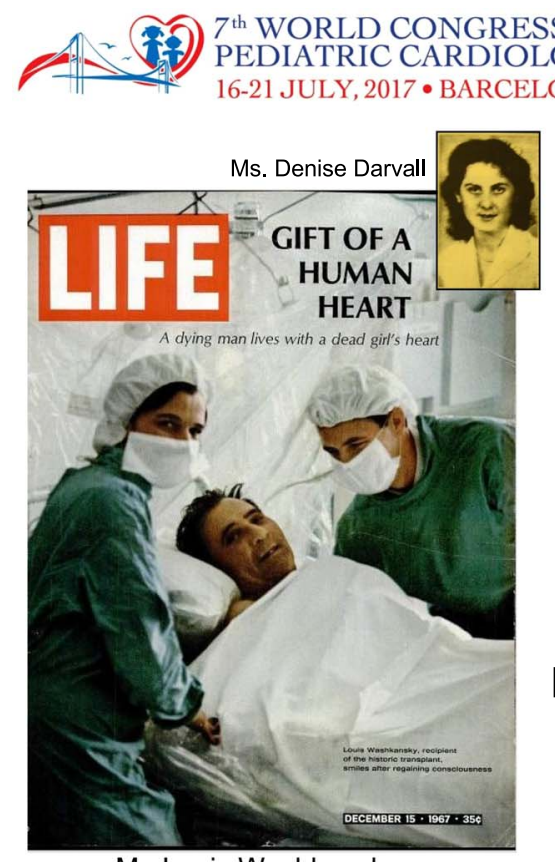

Mr. Louis Washkansky

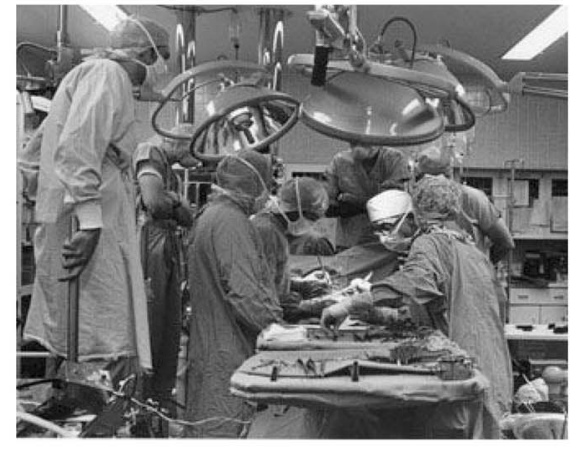

First Human Heart Transplant 3rd December 1967 Capetown, South Africa

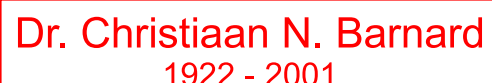

1922 - 2001

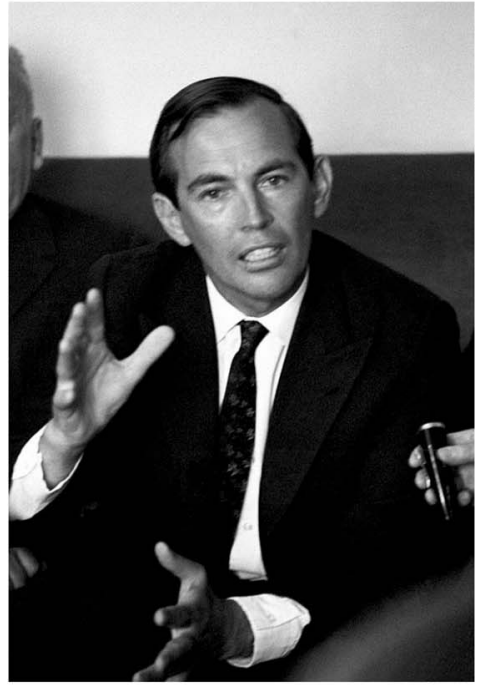

(continued) 
(6)

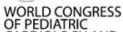

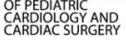

$7^{\text {th }}$ WORLD CONGRESS OF

PEDIATRIC CARDIOLOGY \& CARDIAC SURGERY 16-21 JULY, $2017 \bullet$ BARCELONA
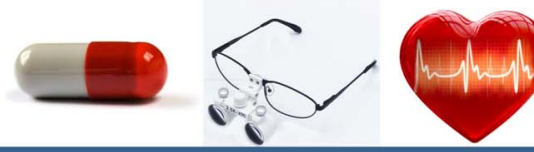

\section{Neonatal Surgery/Early Correction}
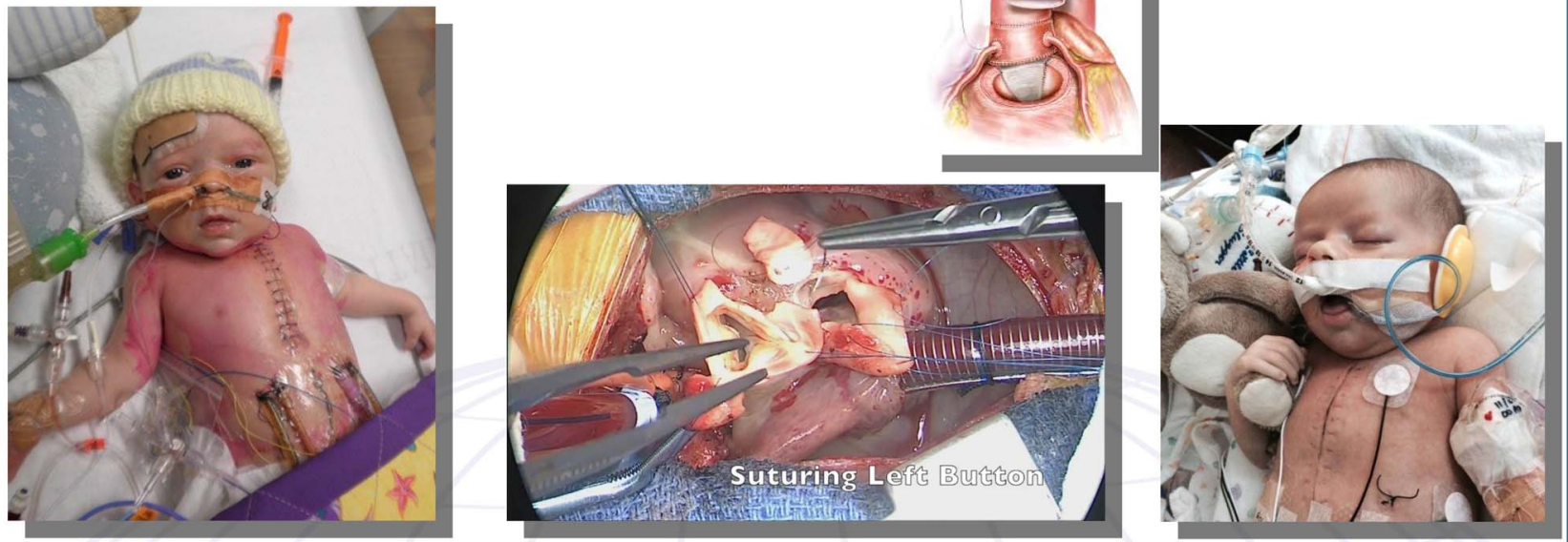